\title{
Dentate gyrus network dysfunctions precede the symptomatic phase in a genetic mouse model of seizures
}

\section{Oana Toader ${ }^{1,2+}$, Nicola Forte ${ }^{1}$, Marta Orlando ${ }^{1}$, Enrico Ferrea ${ }^{1+}$, Andrea Raimondi ${ }^{1+}$, Pietro Baldelli ${ }^{1,3}$, Fabio Benfenati ${ }^{1,3}$ and Lucian Medrihan ${ }^{1 *}$}

\author{
Department of Neuroscience and Brain Technologies, Fondazione Istituto Italiano di Tecnologia, Genoa, Italy \\ 2 International Max-Planck Research School for Neurosciences, Göttingen, Germany \\ ${ }^{3}$ Department of Experimental Medicine, University of Genoa, Genoa, Italy
}

Edited by:

Roberto Di Maio, University of

Pittsburgh, USA

\section{Reviewed by:}

John Huguenard, Stanford

University School of Medicine, USA

Hermona Soreq, The Hebrew

University of Jerusalem, Israel

\section{*Correspondence:}

Lucian Medrihan, Department of

Neuroscience and Brain

Technologies, Fondazione Istituto

Italiano di Tecnologia, Via Morego

30, 16163 Genoa, Italy

e-mail: Iucian.medrihan@iit.it

${ }^{\boldsymbol{t}}$ Present address:

Oana Toader, Department of Clinical Neurobiology, Medical Faculty of

Heidelberg University and German Cancer Research Center (DKFZ),

Heidelberg, Germany;

Enrico Ferrea, Cognitive

Neuroscience Laboratory, German

Primate Center, Leibniz Institute for

Primate Research, Göttingen,

Germany;

Andrea Raimondi, Imaging Research

Center, San Raffaele Scientific

Institute, Milan, Italy
Neuronal circuit disturbances that lead to hyperexcitability in the cortico-hippocampal network are one of the landmarks of temporal lobe epilepsy. The dentate gyrus (DG) network plays an important role in regulating the excitability of the entire hippocampus by filtering and integrating information received via the perforant path. Here, we investigated possible epileptogenic abnormalities in the function of the DG neuronal network in the Synapsin II (Syn II) knockout mouse (Syn II-/-), a genetic mouse model of epilepsy. Syn II is a presynaptic protein whose deletion in mice reproducibly leads to generalized seizures starting at the age of 2 months. We made use of a high-resolution microelectrode array (4096 electrodes) and patch-clamp recordings, and found that in acute hippocampal slices of young pre-symptomatic (3-6 week-old) Syn $\mathrm{I}^{-/-}$mice excitatory synaptic output of the mossy fibers is reduced. Moreover, we showed that the main excitatory neurons present in the polymorphic layer of the DG, hilar mossy cells, display a reduced excitability. We also provide evidence of a predominantly inhibitory regulatory output from mossy cells to granule cells, through feed-forward inhibition, and show that the excitatory-inhibitory ratio is increased in both pre-symptomatic and symptomatic Syn $\mathrm{II}^{-/-}$mice. These results support the key role of the hilar mossy neurons in maintaining the normal excitability of the hippocampal network and show that the late epileptic phenotype of the Syn II-/mice is preceded by neuronal circuitry dysfunctions. Our data provide new insights into the mechanisms of epileptogenesis in the Syn $\mathrm{II}^{-/-}$mice and open the possibility for early diagnosis and therapeutic interventions.

Keywords: epilepsy, synapsins, dentate gyrus, mossy cells, excitatory inhibitory balance

\section{INTRODUCTION}

Epilepsy is a debilitating nervous system disorder mainly characterized by abnormal synchronization of neuronal activity. Current treatments are often unsatisfactory and have undesirable side effects and a number of patients present intractable seizures, for which surgical treatment is the only option (Wilson et al., 1977). This clearly indicates that mechanistically epileptic seizures are far from being understood.

The hippocampal formation is part of the limbic system and represents an important integration site, receiving inputs from most brain areas mainly via the perforant path. Intractable medial temporal lobe epilepsies (MTLE) are often successfully treated by excision of the hippocampus and nearby regions of the brain (Schwartzkroin, 1994). Therefore, this brain area appears to be highly seizure-prone and provides a convenient model to study epileptiform events in vitro. The major subdivisions of the hippocampus are the dentate gyrus (DG) and the cornu ammonis (CA), further divided in the CA3-CA1 regions. The DG has stemmed a lot of interest due to its densely packed, hyperpolarized granule cells thought to have a gate role, filtering synaptic input mainly received from the perforant path (Amaral et al.,
2007). Granule cells are locally regulated by excitatory hilar mossy cells and by several types of inhibitory interneurons (Amaral et al., 2007; Hsu, 2007). There are several theories that propose mossy cells to be key players in hippocampal seizure-like events (Scharfman and Myers, 2012). These are based on several mossy cell characteristics: (i) they are highly excitable and receive input from thousands of granule cells; (ii) they are very sensitive to excitotoxicity; (iii) their axonal projections extend up to millimeters along the septo-temporal axis of the hippocampus, making them suitable candidates for seizure spread; (iv) temporal-lobe epilepsy is often associated with hilar cell loss in patients and in some laboratory models (Santhakumar et al., 2000; Ratzliff et al., 2002; Jinde et al., 2012, 2013; Scharfman and Myers, 2012).

There are several animal models widely used in the study of seizures and epilepsy, both in vitro and in vivo. Acute pharmacological models are obtained mostly by increasing excitation or lowering inhibition (blocking $\mathrm{K}^{+}$-channels with 4-aminopyridine, using a low $\mathrm{Mg}^{2+}$ concentrations in the recording solution to relieve the NMDA receptor $\mathrm{Mg}^{2+}$ block, treatment with bicuculline or penicillin to block $\mathrm{GABA}_{\mathrm{A}}$ receptors) (Gutnick et al., 1982; Voskuyl and Albus, 1985; Witte, 1994; 
Westerhoff et al., 1995). Chronic models are obtained with kainic acid injection, leading to loss of CA3 neurons in the hippocampus (Nadler, 1987), or with pilocarpine injection, causing excessive stimulation of M1 muscarinic receptors in the hippocampus and subsequent neuronal loss (Turski et al., 1983). Another murine epilepsy model, the so-called "kindling" model is based on the finding that repeated seizures can lead to development of epilepsy. Experimental kindling can be triggered, either electrically or chemically, by inducing repeated, short, focal seizures that eventually lead to the appearance of more severe, chronic seizures (Goldberg and Coulter, 2013). The molecular mechanism of kindling is unclear, but there are data supporting the role of BDNF upregulation in the progression of kindling (Garriga-Canut et al., 2006). In all these models of chemically or electrically induced epilepsy, as well as in other models (e.g., stroke or traumatic brain injury), the process of epileptogenesis starts within minutes to months and requires neuroanatomical changes, neural network alterations, activation of inflammatory cascades, post-translational modifications of existing proteins, activation of immediate early genes and several transcriptional changes (Rakhade and Jensen, 2009; Hunt et al., 2013). One comprehensive study evaluated the change in RNA expression across all annotated rat genes after pilocarpine treatment (Okamoto et al., 2010). Overall, there were about 1400 genes that changed their expression throughout the progression of epileptogenesis, with a group of 128 genes that were found to be consistently overexpressed at all stages. The proteins encoded by these genes were involved in the immune response, cell motility, apoptosis, and intracellular signaling cascades (including the mTOR signaling pathways) (Okamoto et al., 2010; Goldberg and Coulter, 2013). This study suggests that epileptogenesis is a highly complex process, involving very diverse groups of genes.

Epilepsy is an inheritable condition and mutations in several genes are associated with seizure disorders in human patients (Poduri and Lowenstein, 2011). Genetic manipulations of these target genes in mice have provided mouse models of epilepsy that are of invaluable help for the understanding of the neuropatophysiological changes in epileptogenesis (Mantegazza et al., 2010). One of the family of genes mutated in several epileptic patients, synapsins (Syns), are a family of abundant neuronal phosphoproteins playing important roles in synaptogenesis, synaptic transmission and plasticity. In mammals, they are encoded by three related genes, SYN1-3 (Kao et al., 1999), translated into ten protein isoforms through alternative splicing (Syn Ia/Ib, Syn IIa/IIb, and IIIa/IIIf) (Cesca et al., 2010; Fassio et al., 2011). The best described function of Syns is the control of neurotransmitter release by clustering synaptic vesicles (SVs) and reversibly tethering them to the actin cytoskeleton, thus maintaining the integrity of the recycling pool (Benfenati et al., 1992). Upon activity-dependent phosphorylation, Syns detach from SVs and render them free to fuse with the plasma membrane (Giovedi et al., 2004; Menegon et al., 2006; Messa et al., 2010). This is an oversimplified view, since experiments have shown that the regulation of neurotransmitter release by Syns is much more subtle and finely tuned (Cesca et al., 2010; Fassio et al., 2011). In both excitatory and inhibitory synapses Syns appear to control downstream events of SV exocytosis, such as docking and fusion and, implicitly, the size of the readily releasable pool (RRP) (Baldelli et al., 2007; Gitler et al., 2008; Valente et al., 2012; Medrihan et al., 2013).

All mutant mice lacking one or more Syn isoforms are prone to epileptic seizures, except for Syn $\mathrm{III}^{-/-}$mice (Cesca et al., 2010) with Syn $\mathrm{II}^{-/-}$mice showing the strongest epileptic phenotype (Etholm et al., 2012). Genetic mapping analysis identified SYN2 among a restricted number of genes significantly contributing to epilepsy predisposition (Cavalleri et al., 2007; Lakhan et al., 2010). Synapsin II appears to have a specific role in preventing synaptic depression and maintaining the SV recycling pool at central excitatory synapses and at the neuromuscular junction (Rosahl et al., 1995; Coleman et al., 2008). Moreover, in DG inhibitory synapses, Syn II controls the dynamics of neurotransmitter release leading to an increase in the RRP responsible for the synchronous release in the detriment of the asynchronous GABA release (Medrihan et al., 2013). Syn II, but also Syn I knockout mice (Syn $\mathrm{I}^{-/-}$and Syn $\mathrm{II}^{-/-}$) present mild emotional memory deterioration as they age (Greco et al., 2013), and are highly seizure prone. After 2-3 months of age, both Syn $\mathrm{II}^{-/-}$mice and Syn $\mathrm{I}^{-/-}$mice become epileptic and exhibit partial, secondarily generalized epileptic seizures triggered by novelty stimuli such as handling, loud noise or mating (Etholm et al., 2012). One of the most important questions regarding the Syn $\mathrm{II}^{-/-}$mouse epileptic model concerns the absence of seizures before the age of 2 months. Our aim in this study was to investigate the neuronal function in the pre-symptomatic phase of this mouse model. Given the large body of experimental evidence pointing toward the importance of the DG in epileptogenesis, here we have searched for pathological impairments of its circuitry in pre-symptomatic Syn $\mathrm{II}^{-/-}$mouse brain slices, using a combination of electrophysiological and morphological techniques.

\section{MATERIALS AND METHODS ANIMALS}

Experiments were performed on 3-6 weeks (pre-symptomatic animals) or 4-6 months-old (after seizure onset) homozygous Syn II knockout (Syn II-/-) mice generated by homologous recombination and age-matched $\mathrm{C} 57 \mathrm{BL} / 6 \mathrm{~J}$ wild-type (WT) animals. All experiments were carried out in accordance with the guidelines established by the European Community Council (Directive 2010/63/EU of September 22nd, 2010) and were approved by the Italian Ministry of Health. Adequate measures were always taken to minimize animal pain or discomfort.

\section{PREPARATION OF SLICES}

Mice were anesthetized with isofluran by inhalation, decapitated and the brain dissected out in ice cold cutting solution containing (mM): $87 \mathrm{NaCl}, 25 \mathrm{NaHCO}_{3}, 2.5 \mathrm{KCl}, 1.25 \mathrm{NaH}_{2} \mathrm{PO}_{4}, 0.5 \mathrm{CaCl}_{2}$, $7 \mathrm{MgCl}_{2}, 25$ glucose, and 75 sucrose saturated with $95 \% \mathrm{O}_{2}$ and $5 \% \mathrm{CO}_{2}$. Horizontal, $400 \mu \mathrm{m}$ thick, cortico-hippocampal slices were cut using a Microm HM $650 \mathrm{~V}$ vibratome equipped with a Microm CU 65 cooling unit (Thermo Fisher Scientific, Waltham $M A, U S A)$. Slices were cut at $2^{\circ} \mathrm{C}$ in the bath solution. After cutting, slices were left to recover for $45-60 \mathrm{~min}$ at $35^{\circ} \mathrm{C}$ and for another hour at room temperature in artificial cerebrospinal fluid 
(aCSF) containing in mM: $125 \mathrm{NaCl}, 25 \mathrm{NaHCO}_{3}, 25$ glucose, 2.5 $\mathrm{KCl}, 1.25 \mathrm{NaH}_{2} \mathrm{PO}_{4}, 2 \mathrm{CaCl}_{2}$, and $1 \mathrm{MgCl}_{2}$ (bubbled with $95 \%$ $\mathrm{O}_{2}-5 \% \mathrm{CO}_{2}$ ). The same solution was used for the perfusion of slices during recordings.

\section{PATCH-CLAMP RECORDINGS}

Whole-cell recordings were performed with a Multiclamp 700B/Digidata1440A system (Molecular Devices, Sunnyvale, CA) using an upright BX51WI microscope (Olympus, Tokyo, Japan). For all experiments we used a high-K gluconate intracellular solution containing (in $\mathrm{mM}$ ): $126 \mathrm{~K}$ gluconate, $4 \mathrm{NaCl}, 1 \mathrm{MgSO}_{4}, 0.02$ $\mathrm{CaCl}_{2}, 0.1$ BAPTA, 15 Glucose, 5 HEPES, 3 ATP, and 0.1 GTP. The $\mathrm{pH}$ was adjusted to 7.3 with $\mathrm{KOH}$ and osmolarity was adjusted to $290 \mathrm{mosmol} / \mathrm{l}$ using sucrose. Patch-pipette resistance was 3-6 $\mathrm{M} \Omega$ when filled with intracellular solution. Somatic access resistance $\left(\mathrm{R}_{\mathrm{a}}\right)$ was continuously monitored, and cells with unstable $R_{a}$ (20\% changes) or with values larger than $15 \mathrm{M} \Omega$ were excluded from the analysis.

Mossy cells were identified by their shape, which has a triangular appearance in an infrared differential interference contrast image, size (mossy cells are clearly larger that surrounding interneurons) and location (deep hilus). Mossy cells were also filled with AlexaFluor $568(40 \mu \mathrm{M}$ in the pipette solution) to make the specific complex spines (named thorny excrescences) on the proximal dendrites visible in epifluorescence imaging (see Figure 4C). For cells that could not be clearly visualized, electrophysiological features, such as firing frequency adaptation during positive current injection, reduced afterhyperpolarization, broad action potentials, and high frequency/large amplitude spontaneous excitatory postsynaptic currents (sEPSPs) in the presence of bicuculline/CGP 55845, were used to identify them. Intrinsic cell properties were calculated from recordings performed in the presence of $50 \mu \mathrm{M}$ D-APV, $10 \mu \mathrm{M}$ CNQX, $5 \mu \mathrm{M}$ CGP 55845, and $30 \mu \mathrm{M}$ bicuculline. For the recording of miniature excitatory postsynaptic currents (mEPSCs), aCSF cointaining $5 \mu \mathrm{M}$ CGP $55845,30 \mu \mathrm{M}$ bicuculline, and $0.3 \mu \mathrm{M}$ TTX was used. All experiments were performed at a holding potential $\left(V_{h}\right)$ of $-70 \mathrm{mV}$ in the presence of $30 \mu \mathrm{M}$ bicuculine and $5 \mu \mathrm{M}$ CGP 55845 (all from Tocris Bioscience, Ellisville, MO).

Granule neurons were selected based on their oval shape and their middle position in the granule layer. Since dentate granule neurons can be in different stages of maturation we recorded only mature neurons in which $R_{m}<300 \mathrm{M} \Omega$ (Liu et al., 1998).

In experiments where extracellular stimulation was performed, a monopolar stimulation electrode (a glass pipette filled with aCSF) was placed in the hilus, close to the granule cell layer and connected to an external stimulator (A-M Systems, Sequim $W A)$.

\section{PATCH-CLAMP DATA ANALYSIS}

All data were acquired with Clampex and analyzed offline with Clampfit 10.2 (Molecular Devices, Sunnyvale CA, USA), MiniAnalysis (Synaptosoft, Decatur GA, USA), Excel and GraphPad.

In the current-clamp mode, 30 current steps lasting $1 \mathrm{~s}$, starting from $-100 \mathrm{pA}$ in $10 \mathrm{pA}$ increments, were applied to both granule and mossy cells. To precisely determine the resting membrane potential $\left(V_{m}\right)$ value, this was continuously recorded for $1 \mathrm{~min}$, plotted in a histogram, and fitted with a Gaussian curve. $V_{m}$ was taken as the mean of the distribution. To determine the start $\left(V_{s}\right)$ of an action potential $(A P)$, phase plane plots were constructed and $V_{s}$ was considered the voltage point where $\mathrm{dV} / \mathrm{dt}$ exceeded $10 \mathrm{mV} / \mathrm{ms}$. The AP amplitude was measured as the difference between the maximum voltage reached during the overshoot minus $V_{s}$. The afterhyperpolarization (AHP) value was considered as the point where $d V / d t$ was equal to zero, after the repolarization phase. The rheobase was estimated as the smallest current step that elicited an AP. For calculating the input resistance $\left(R_{\mathrm{in}}\right)$, the steady state voltage values from the first step above and below zero current $(-10$ and $+10 \mathrm{pA})$, plus the zero current trace were plotted against the injected current and fitted with a linear regression. $R_{\text {in }}$ was taken as the slope of the fitting line. The coefficient of determination $\mathrm{R}^{2}$ was always higher than 0.95 .

For the analysis of mEPSCs, $30 \mathrm{~s}$ of each recording were imported into MiniAnalysis (Synaptosoft Inc., New Jersey). Events' peaks were identified manually because of the presence of multipeak events due to the high frequency of spontaneous events. Subsequently, the software automatically calculated amplitude, rise, and decay. Minimum amplitude threshold was set to $8 \mathrm{pA}$. For the analysis of mEPSC kinetics, a set of individual 40-60 events was chosen in which the rise and the decay phase were very clear. The events were all aligned at the point of 50\% rise and averaged for further calculations. The decay phase was best fitted with a monoexponential equation on the $90-10 \%$ decay phase. The cumulative distributions of amplitudes and frequencies were constructed by pooling all values, and analyzed with a Kolmogorov-Smirnov test for distributions.

\section{HIGH-DENSITY ACTIVE-PIXEL-SENSOR MICROELECTRODE ARRAY (MEA) RECORDINGS}

The APS-MEA, extensively described elsewhere (Ferrea et al., 2012), consists of a microelectrode array chip and an amplification system designed to provide simultaneous extracellular recordings from 4096 electrodes at a sampling rate of $7.7 \mathrm{kHz}$. Each square pixel measures $21 \times 21 \mu \mathrm{m}$, and the array is integrated with an electrode pitch (center-to-center) of $42 \mu \mathrm{m}$. Pixels are arranged in a $64 \times 64$ array configuration, yielding an active area of $7.22 \mathrm{~mm}^{2}$, with a pixel density of 567 pixels $/ \mathrm{mm}^{2}$. The three on-chip amplification stages provide a global gain of $60 \mathrm{~dB}$, with a $0.1-5 \mathrm{kHz}$ band-pass filter. This bandwidth is suitable for recording both slow LFP signals and fast APs. The acquisition is controlled by the BrainWave software (3Brain Gmbh, Switzerland). For stimulation experiments of the DG, a monopolar stimulation electrode placed on the medial perforant path and connected to an external stimulator ( $A-M$ Systems, Sequim WA) was used. Clear evoked responses separated from the stimulation artifact were obtained using stimulation intensities between 100 and $500 \mu \mathrm{A}$ (for $30 \mu \mathrm{s}$ ). Large-scale field recordings were acquired using BrainWave and analyzed offline with MatlabR2010a, Clampfit 10.2 and ImageJ. For the analysis of the peak amplitude, 3 representative channels (named "pixels") from the molecular layer and 3 from the hilus were exported in Matlab (MathWorks, http://www. mathworks.it/) and then imported in Clampfit for analysis. The 
maximum amplitude of the evoked events on each channel was measured, averaged (10 events/experiment) and normalized to the control amplitude. For the analysis of the mean amplitude for the entire area, an image at the point of highest response for the respective area was imported in ImageJ and the mean intensity was calculated after normalization of the maximum intensity to the maximum voltage of the same response.

\section{IMMUNOFLUORESCENCE}

WT and Syn $\mathrm{II}^{-/-}$mice were deeply anesthetized with $20 \%$ urethane $(0.1 \mathrm{ml} / 10 \mathrm{gm})$ and perfused transcardially with $0.1 \mathrm{M}$ phosphate buffer containing 4\% paraformaldehyde ( $\mathrm{pH} 7.4$ ). Brains were subsequently postfixed overnight in paraformaldehyde solution, and then washed in PBS, infiltrated with a $30 \%$ sucrose PBS solution for cryoprotection and frozen in OCT. Ten $\mu \mathrm{m}$ thick horizontal sections were cut using a Leica CM3050 $\mathrm{S}$ Cryostat and collected on SuperFrost slides. Sections were incubated $1 \mathrm{~h}$ in blocking buffer (2\% NGS, 1\% BSA, 0.1\% CFG, $0.1 \%$ Triton $\mathrm{X}-100,0.05 \%$ Tween in PBS), then for $2 \mathrm{~h}$ in blocking buffer containing primary antibodies. After several washes in PBS, sections were incubated with blocking buffer containing fluorochrome-conjugated secondary antibodies (Invitrogen, 1:500), washed and mounted using Prolong Gold antifade reagent with DAPI staining (Invitrogen) for fluorescence microscopy observation on a Leica SP5 confocal laser scanning fluorescence microscope. The mean fluorescence intensity ratio between Syn I or Syn II and calretinin were calculated with the software ImageJ. Antibodies used were: Anti-Synapsin 1 (Mouse, 1:500, SYSY \#106 001; Rabbit, 1:200 G-177), Anti-Synapsin 2 (Mouse, 1:200, clone 19.21), Anti-panSynapsins (Rabbit, 1:500 G143), Anti-Calretinin (Guinea Pig, 1:1000, SYSY\# 214 104).

\section{ELECTRON MICROSCOPY}

Acute slices were fixed by immersion in $1.3 \%$ glutaraldehyde in $66 \mathrm{mM}$ sodium cacodylate buffer. Subsequently, slices were post-fixed with $1 \% \mathrm{OsO} 4$ in $1.5 \% \mathrm{~K}_{4} \mathrm{Fe}(\mathrm{CN})_{6}$ in $0.1 \mathrm{M}$ sodium cacodylate, en bloc stained with $0.5 \%$ uranyl acetate, dehydrated through a series of graded ethanol solutions, washed in propylene oxide and flat embedded in Embed 812 between two Aclar sheets. After $48 \mathrm{~h}$ of polymerization at $60^{\circ} \mathrm{C}$, a small region corresponding to the DG was excised, glued with cyanoacrylate glue on blocks of resin and cut with a Leica EM UC6 ultramicrotome. Ultrathin sections (thickness: $70-90 \mathrm{~nm}$ ) were collected on Formvar carbon coated copper grids. Grids were observed in a JEOL JEM-1011 microscope operating at $100 \mathrm{kV}$ using an ORIUS SC1000 CCD camera (Gatan). Total and docked SV densities were calculated using the software ImageJ.

\section{STATISTICAL ANALYSIS}

All data are expressed as means \pm s.e.m. All statistics were performed with GraphPad Prism. For comparison between WT vs. Syn $\mathrm{II}^{-/-}$experiments, two-tailed unpaired Student's $t$-test was used. For multiple comparisons, one or two-way analysis of variance (ANOVA) with Bonferroni post-hoc test or Kruskal-Wallis test followed by Dunn's post-hoc test was used, depending on the type of data. The level of significance was set at $p<0.05$.

\section{RESULTS \\ NETWORK IMPAIRMENTS OF DG IN PRE-SYMPTOMATIC SYN II-/- MICE}

Our first step was to investigate the response of different areas of the DG to the stimulation of the perforant path in horizontal brain slices containing the hippocampus and rhinal cortices from pre-symptomatic (3-6 weeks) Syn $\mathrm{II}^{-/-}$mice. To this aim, we employed a high-resolution Active Pixel Sensor microelectrode array system (APS-MEA, 4096 electrodes: see Materials and Methods) (Ferrea et al., 2012). Field postsynaptic potentials (fPSPs), evoked by the stimulation of the perforant path with an extracellular electrode, were detected in the granule layer of the DG and they further propagated to the hilus (Figure 1A). The mean amplitude of the response, calculated over the entire activated region in the granule cell layer, was similar in WT and Syn $\mathrm{II}^{-/-}$slices $(153.7 \pm 15.2 \mu \mathrm{V}$ for WT vs. $135.6 \pm 10.6 \mu \mathrm{V}$ for Syn $\mathrm{II}^{-/-}, n=13$ slices for each genotype; two-tailed unpaired Student's $t$-test, $p=0.342$ ) (Figures 1B,D). On the other hand, the mean amplitude of the response in the hilar region was significantly reduced in Syn $\mathrm{II}^{-/}$slices $\left(143.0 \pm 19.4 \mu \mathrm{V}\right.$ for WT vs. $87.13 \pm 10.7 \mu \mathrm{V}$ for Syn $\mathrm{II}^{-/-}$, $n=12$ slices for each genotype; two-tailed unpaired Student's $t$-test, $p=0.013$ ) (Figures 1C,D). The stimulus amplitude was set to $400-500 \mu \mathrm{A}$ based on previous input-output curves performed for 3 selected electrodes in each of the two regions. At all stimulation intensities, a reduced amplitude of the responses in the Syn $\mathrm{II}^{-/-}$hilar region with respect to the WT was observed (Figures 1E,F). The recorded signal on several neighboring electrodes on the APS-MEA correlated with the fine anatomy of the DG and its polarity corresponded to current sinks in the dendritic-granule layer (negative) and to current sources in the hilus (positive) (Figure 1D). Moreover, the propagation time of the evoked fPSP, measured between the peaks of the response from one representative electrode in the granule and hilar regions, was significantly longer in Syn $\mathrm{II}^{-/-}$than in WT slices $(2.8 \pm$ $0.78 \mathrm{~ms}$ for WT vs. $5.6 \pm 0.59 \mathrm{~ms}$ for Syn $\mathrm{II}^{-/-}, n=6 / 5$ slices; two-tailed unpaired Student's $t$-test, $p=0.032$ ) (Figure 1G), suggesting the presence of functional impairments of the hilar region.

The hilus of the DG contains hilar mossy cells and inhibitory interneurons, whose activity modulate the excitability of granule neurons (Scharfman and Myers, 2012), by forming a regulatory loop. We have previously shown that the plasticity of the young Syn $\mathrm{II}^{-/-}$excitatory and inhibitory synapses upon train stimulation of the perforant path does not significantly differ from that of WT synapses (Medrihan et al., 2013). Since we observed a reduced signal in the hippocampal hilus, we reasoned that a sustained train of stimuli would reveal possible dysfunctions of the granule layer-hilus network function. Thus, we stimulated the perforant path with a train of $20 \mathrm{~Hz}$ for $5 \mathrm{~s}$ and measured the ratio between the first and the last evoked fPSP response of the train over the entire granule cell layer area (Figures 2A,B). To our surprise, the depression induced by a train of stimuli was significantly higher in WT than in Syn $\mathrm{II}^{-/-}$slices $(0.45 \pm 0.03$ for WT vs. $0.73 \pm 0.08$ for Syn $\mathrm{II}^{-/-}, n=4 / 5$ slices; two-tailed unpaired Student's $t$-test, $p=$ 0.033) (Figure 2C). Based on previous results showing that 

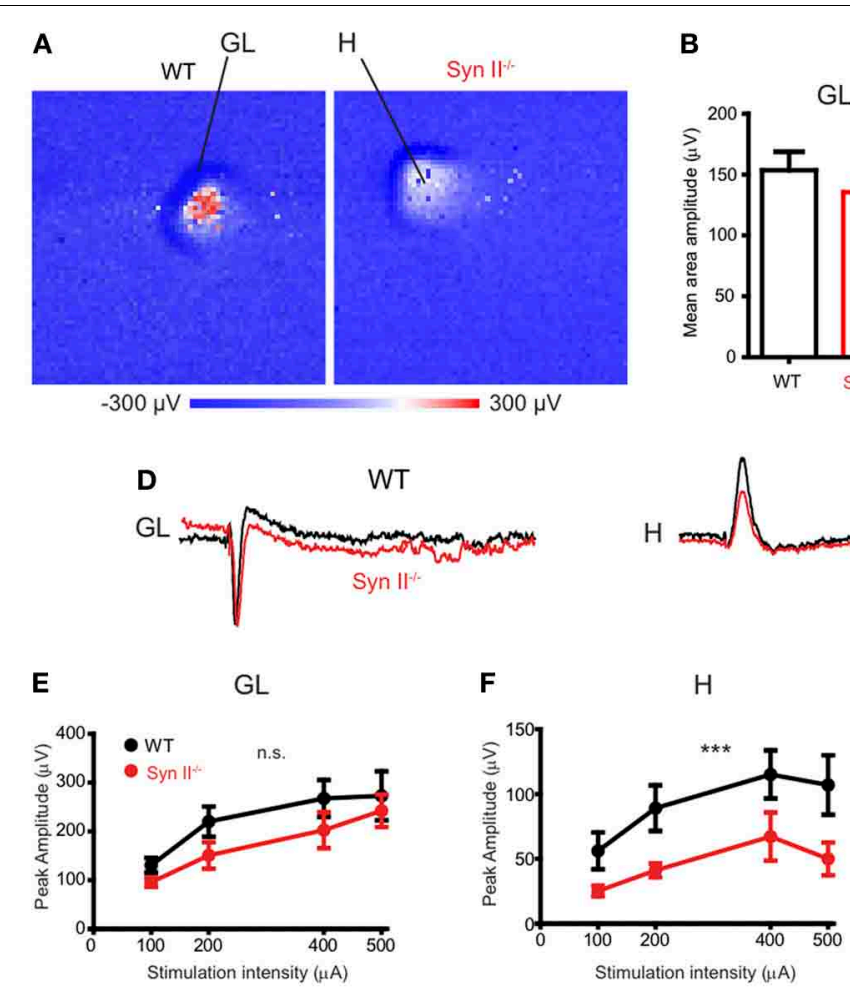

B

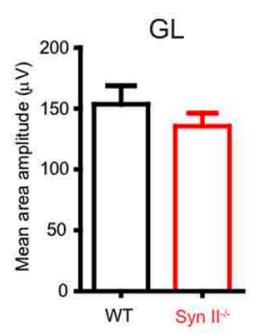

C

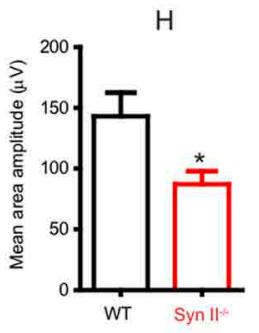

FIGURE 1 | APS-MEA extracellular field recordings show decreased activity in the hilus upon stimulation of the perforant path. (A) Color-coded fPSP activity in the entire APS-MEA chip (each pixel represents one electrode) in WT and pre-symptomatic Syn $\mathrm{II}^{-/}$- slices with arrows showing the activated areas ( $G L$, granule layer; $H$, hilus) upon perforant path stimulation. (B,C) Mean ( \pm s.e.m.) amplitude of the entire response area from WT and pre-symptomatic Syn $\mathrm{II}^{-/-}$in the granule layer (B) and hilus (C); ${ }^{*} p<0.05$, two-tailed unpaired Student's t-test. (D) Representative traces from one APS-MEA electrode from both genotypes located in the granule layer and hilus, respectively. (E,F) Stimulation-response curves representing the mean ( \pm s.e.m.) peak amplitudes of three randomly selected electrodes from the granule layer (E) or hilus (F) at increasing stimulation intensities; ${ }^{* *} p<0.001$, Two-Way ANOVA. (G) Mean ( \pm s.e.m.) stimulus propagation time from $\mathrm{GL}$ to $\mathrm{H}$ at a stimulation intensity of $500 \mu \mathrm{A} ;{ }^{*} p<0.05$, two-tailed unpaired Student's t-test. perforant path plasticity is unaltered in Syn $\mathrm{II}^{-/-}$, these results point toward a reduced feedback inhibition of the granule cell layer.

\section{SYNAPSIN II IS ABUNDANTLY EXPRESSED IN TERMINALS OF BOTH GRANULE AND MOSSY NEURONS}

Next, we confirmed the presence of Syn II in the DG. Acute brain slices from 6 weeks old WT mice were immunolabeled for endogenous Syns I and II and for the mossy cell marker calretinin (Blasco-Ibanez and Freund, 1997) (Figure 3A). Since in some species calretinin is also a marker for GABAergic interneurons (Scharfman and Myers, 2012), we co-immunolabeled for GABA and noticed that calretinin immunoreactive hilar cells are negative for GABA (data not shown), suggesting that they are indeed hilar mossy cells. Both Syn I and Syn II puncta were abundantly observed in the hilar region of the DG, where mossy fiber terminals are localized. Remarkably, Syn II, but not Syn I, positive puncta were present in high density in the inner molecular layer, colocalizing with the hilar cell terminals. We therefore measured the mean intensity ratio between either Syn isoform and calretinin in the inner molecular layer of the DG $(0.09 \pm 0.007$ for Syn I/calretinin and $0.61 \pm 0.11$ for Syn II/calretinin, $n=3$ mice; two-tailed unpaired Student's $t$-test, $p=0.034)$ and in the hilar region $(0.195 \pm 0.0994$ for Syn $\mathrm{I} /$ calretinin and $0.229 \pm 0.1157$ for Syn II/calretinin, $n=3$ mice; two-tailed unpaired Student's $t$-test, $p=0.837$ ) (Figures 3B-D). To further prove the specific presence of Syn II at mossy cell terminals, we stained brain slices from Syn $\mathrm{I}^{-/-}$and Syn $\mathrm{II}^{-/-}$ mice respectively for calretinin (red) and all Syn isoforms (pansynapsin antibody, green). While in the Syn $\mathrm{I}^{-/-}$slices the pansynapsin staining is visible in the IML, it was completely absent in the same region of the Syn $\mathrm{II}^{-/-}$slices (Figure 3E, bottom panels).

\section{REDUCED SYNAPTIC ACTIVITY IN MOSSY CELLS FROM PRE-SYMPTOMATIC SYN II-/- MICE}

Since we noticed an impaired function of the hilar region of the DG (Figure 1) and Syn II is highly expressed at the mossy fiber terminals (Figure 3), we next investigated the synaptic input received by hilar mossy cells from granule neurons. First, we used electron microscopy to morphologically evaluate the number and spatial distribution of SVs within the mossy fiber terminals in the hilar region of the DG of pre-symptomatic Syn $\mathrm{II}^{-/-}$and WT mice (Figure 4A). The total density of SVs in Syn $\mathrm{II}^{-/-}$synapses 


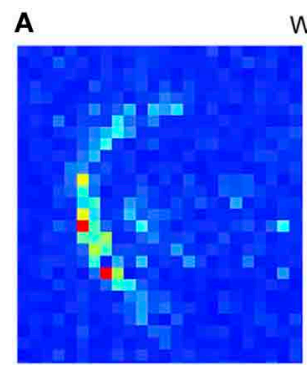

WT

$0 \mu \mathrm{V}$

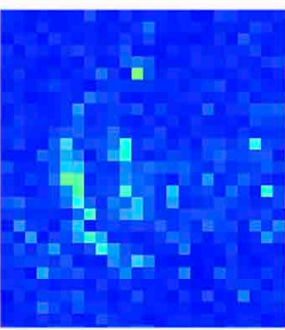

$300 \mu \mathrm{V}$

B

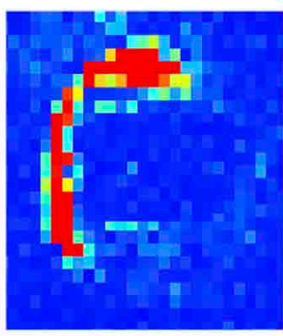

Syn $11^{\%}$

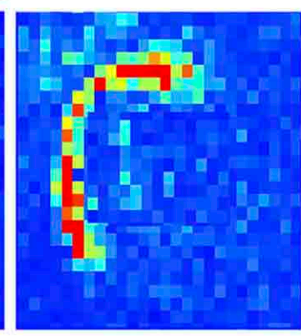

$0 \mu \mathrm{V}$ $300 \mu \mathrm{V}$

c

GL

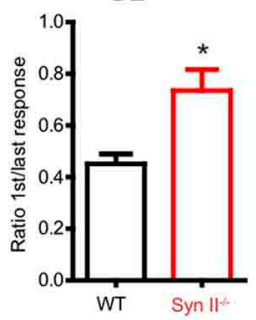

FIGURE 2 | Perforant path depression is reduced in slices from young Syn III $^{-/}$mice. (A,B) Color-coded fPSP activity on a selected area on the APS-MEA chip representing the response of the DG granule layer from WT (A) and pre-symptomatic Syn $\mathrm{I}^{-/-}$(B) slices to the first (left) and the last (right) perforant path extracellular stimulation in a train of $5 \mathrm{~s}$ at $20 \mathrm{~Hz}$. (C) Mean ( \pm s.e.m.) ratio between the mean granule layer amplitude of the first and the last response in the train for both genotypes; ${ }^{*} p<0.05$, two-tailed unpaired Student's $t$-test.

was significantly lower than that of WT synapses $(198.7 \pm 13.7$, $n=44$ terminals $/ 3$ mice and $89.27 \pm 10.8 \mathrm{SVs} / \mu \mathrm{m}^{2}, n=51$ terminals/ 3 mice, for WT and Syn $\mathrm{II}^{-/-}$respectively; two-tailed unpaired Student's $t$-test, $p=0.0003$; Figures 4A,B). However, the number of docked SVs did not differ between genotypes (9.42 $\pm 0.6, n=19$ terminals $/ 3$ mice and $9.70 \pm 0.7 \mathrm{SVs} / \mu \mathrm{m}$, $n=19$ terminals/ 3 mice, for $\mathrm{WT}$ and Syn $\mathrm{II}^{-/-}$respectively; twotailed unpaired Student's $t$-test, $p=0.782$ ) (Figures $4 \mathbf{A}, \mathbf{B}$ ), as previously reported for Syn deletions at various synapses (Gitler et al., 2004; Medrihan et al., 2013).

To functionally analyze these synapses, we recorded mEPSCs from pre-symptomatic Syn $\mathrm{II}^{-/-}$hilar mossy cells after blocking GABA receptors and $\mathrm{Na}^{+}$channels with bicuculline $(30 \mu \mathrm{M})$, CGP55845 $(5 \mu \mathrm{M})$ and TTX $(0.3 \mu \mathrm{M})$. To distinguish mossy cells from the surrounding hilar neurons, we filled the patch pipette with AlexaFluor568-containing intracellular

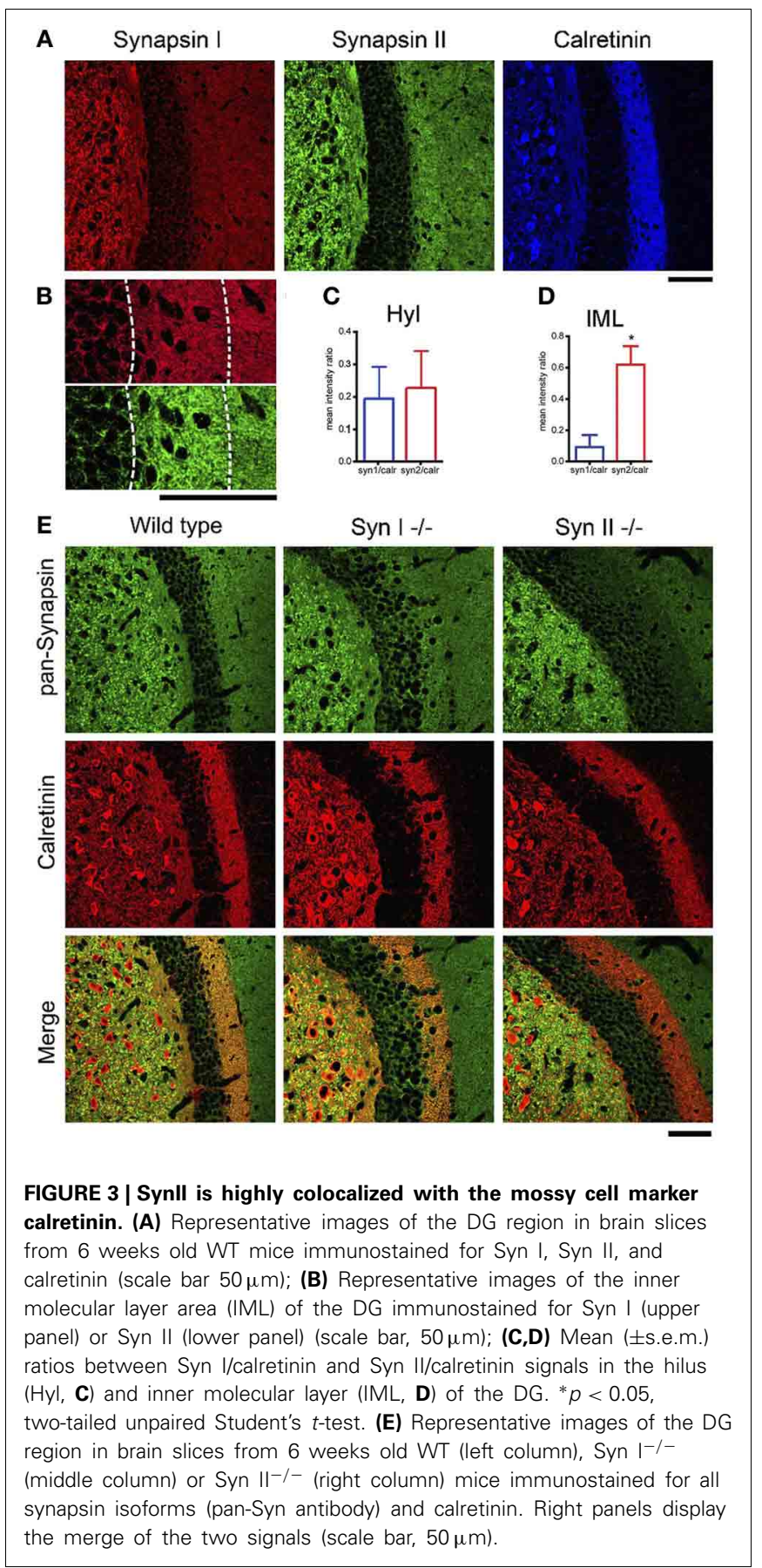

solution. This enabled the detection of moss-resembling spines (called "thorny excrescences") present on the proximal dendrites of these cells (Figure 4C). As reviewed before (Henze and Buzsaki, 2007; Scharfman and Myers, 2012), hilar mossy cells are highly excitable, receiving massive input from the mossy fibers, and their mEPSCs have an unusually large amplitude and frequency in comparison with other central synapses (Figure 4D). Both the amplitude and the frequency distributions of mEPSCs were significantly shifted toward smaller values in Syn $\mathrm{II}^{-/-}$hilar mossy neurons $(n=11$ neurons/7 mice for WT and 6 neurons/3 mice for Syn $\mathrm{II}^{-/-}$; Kolmogorov-Smirnov test, 


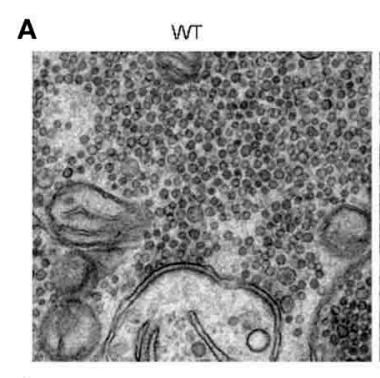

c
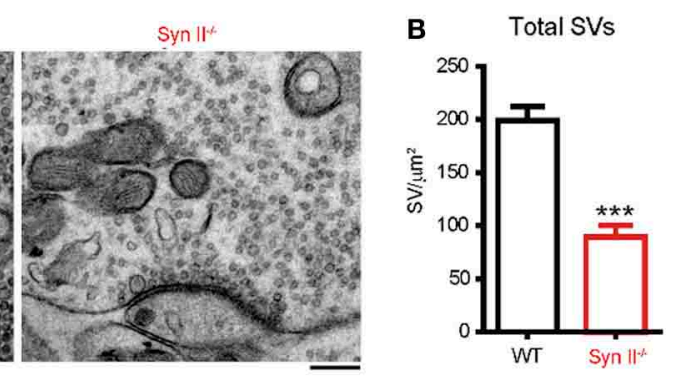

Docked SVs

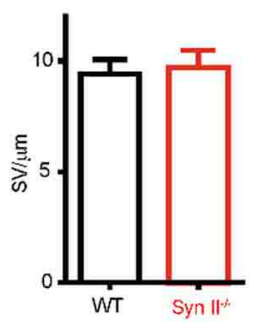

D

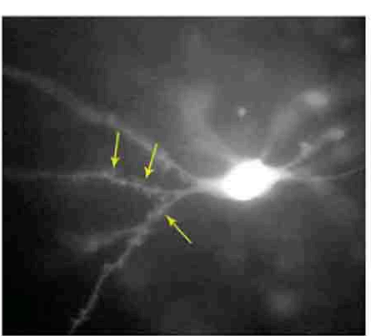

E

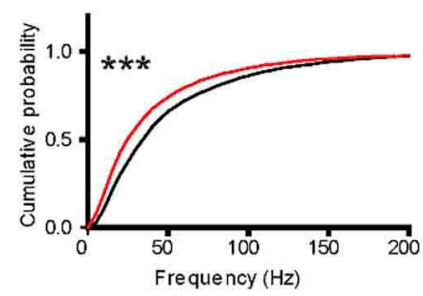

WT

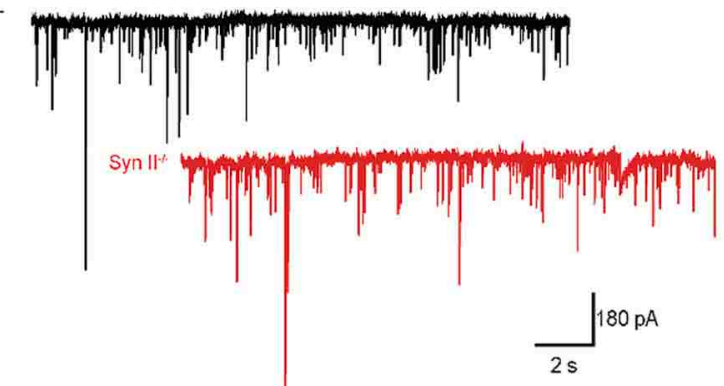

$\mathbf{F}$
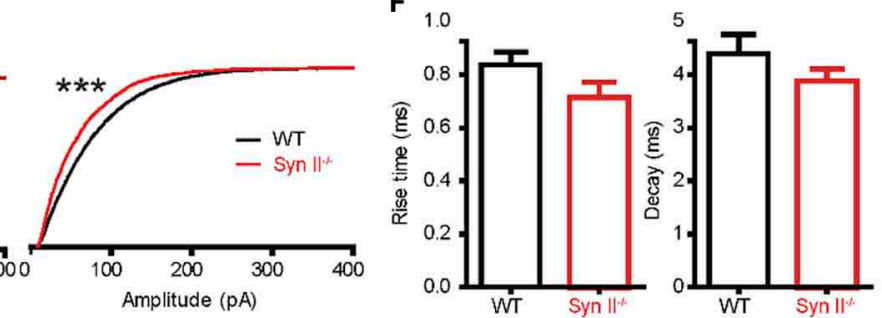

FIGURE 4 | A decreased number of mossy fiber synaptic vesicles is associated with reduced $\mathrm{mEPSC}$ frequency and amplitude in mossy cells from pre-symptomatic Syn $\mathbf{I I}^{-/-}$mice. (A) Transmission electron microscopy images of mossy fiber terminals in the DG hilus of brain slices from WT (black bars) and pre-symptomatic Syn $\mathrm{II}^{-/-}$(red bars) mice (scale bar $200 \mathrm{~nm}$ ). (B) Mean ( \pm s.e.m.) density of total SVs and number of docked SVs in presynaptic terminals of WT and Syn $\mathrm{II}^{-/-}$ neurons; ${ }^{* * *} p<0.001$, two-tailed unpaired Student's $t$-test. (C)

Representative Syn $\mathrm{II}^{-/-}$hilar mossy cell patch-clamped in an acute brain slice and filled with AlexaFluor568. Yellow arrows point toward thorny excrescences that are visible in the focal plane. (D) Representative mEPSC traces recorded in mossy cells from WT (black lines) and pre-symptomatic Syn $\|^{-/-}$(red lines) mice in the presence of GABA receptor and $\mathrm{Na}^{+}$channel blockers. (E) Cumulative distributions of the amplitudes and frequencies of mEPSCs in WT and Syn $\mathrm{II}^{-1-}$ neurons; ${ }^{* * *} p<0.001$, Kolmogorov-Smirnov test. (F) Mean ( \pm s.e.m.) rise-time $(10-90 \%)$ and mono-exponential $\tau$ of decay of mEPSCs from WT (black bars) and Syn $\|^{-/-}$(red bars) neurons. $p<0.001$ ) (Figure 4E). Such a leftward shift of frequencies indicates the presence of a presynaptic involvement. Although the distribution of mEPSC amplitudes in Syn $\mathrm{II}^{-/-}$was also left-shifted, it was not associated with a change in the kinetic parameters of the response (rise-time 10-90\%: $0.83 \pm 0.04$ vs. $0.71 \pm 0.05 \mathrm{~ms}$, $p=0.168$; decay $\tau: 4.39 \pm 0.35$ vs. $3.87 \pm 0.23 \mathrm{~ms}, p=0.374$; two-tailed unpaired Student's $t$-test) (Figure 4F), suggesting an overall decreased excitatory presynaptic input on Syn $\mathrm{II}^{-/-}$hilar mossy cells from young mice.

\section{HILAR MOSSY CELLS OF PRE-SYMPTOMATIC SYN II-/- MICE DISPLAY DECREASED EXCITABILITY}

Extracellular fPSPs are the summation of a series of events, notably synaptic activity and synchronous firing of APs by groups of neurons (Buzsaki et al., 2012). Thus, in the next experiment, we evaluated the firing rate of hilar mossy neurons from pre-symptomatic Syn $\mathrm{II}^{-/}$in the current clamp configuration.
In the presence of specific antagonists that fully block synaptic activity, mossy cells were injected with 30 current steps, lasting $1 \mathrm{~s}$ and ranging from -100 to $+200 \mathrm{pA}$, in $10 \mathrm{pA}$ increments (Figures 5A,B). The firing rate of mossy neurons was lower in Syn $\mathrm{II}^{-/}$- slices with respect to WT recordings (Figure 5B) and was accompanied by a significant increase in the rheobase $(45.0 \pm 6.7$, $n=11$ neurons $/ 5$ mice for WT vs. $83.3 \pm 8.8$ for Syn $\mathrm{II}^{-/-}$, $n=6$ neurons $/ 4$ mice; two-tailed unpaired Student's $t$-test, $p=$ 0.003 ) (Figure 5C, left). Input resistance, a parameter correlated with the firing rate, was also significantly reduced in Syn $\mathrm{II}^{-/-}$ (396.0 $\pm 45.2 \mathrm{M} \Omega, n=11$ neurons/5 mice for WT vs. $248.7 \pm$ 23.2 for Syn $\mathrm{II}^{-/-}, n=6$ neurons/4 mice; two-tailed unpaired Student's $t$-test, $p=0.031$ ) (Figure 5C, right). On the contrary, recording from granule cells revealed no differences in the firing rates of WT and Syn $\mathrm{II}^{-/-}$neurons (Figures 5D,E), with no genotype-dependent difference in either input resistance or rheobase (data not shown). Other intrinsic membrane properties 


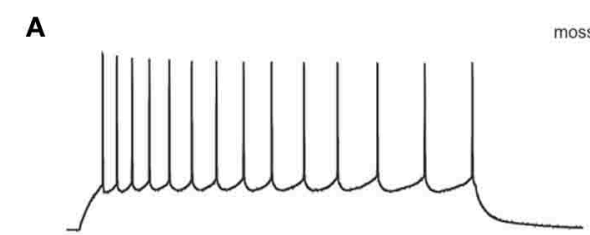

B

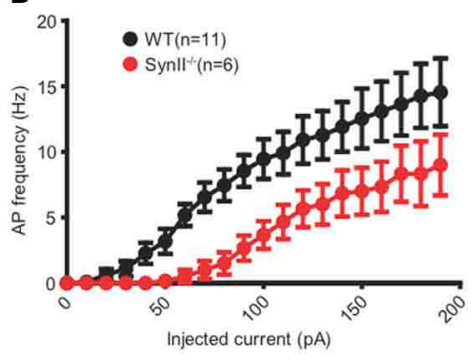

D

granule cells

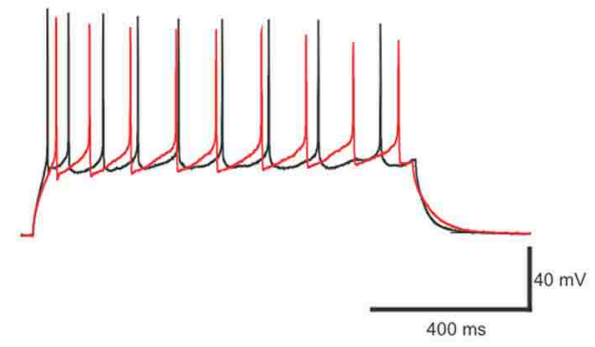

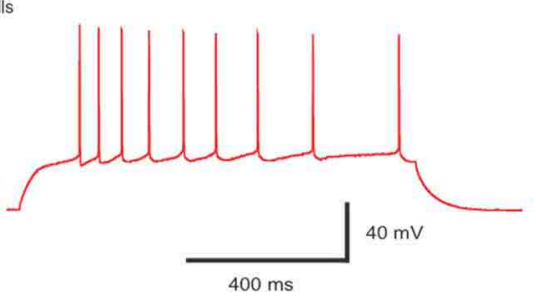

C
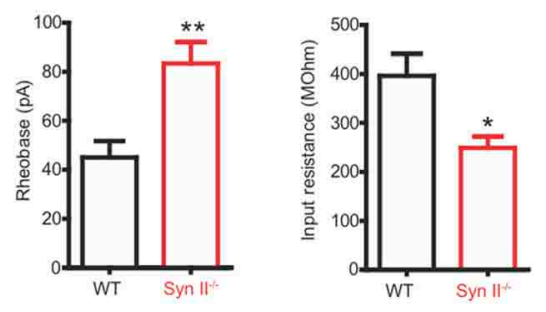

E

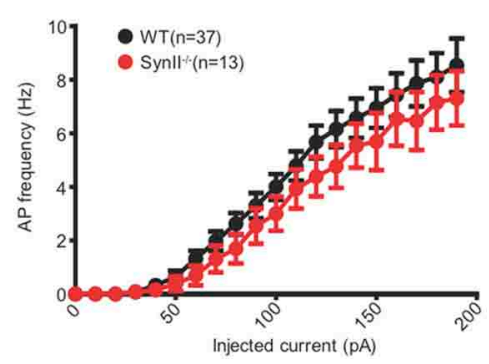

(C) Mean ( \pm s.e.m.) rheobase and input resistance; ${ }^{*} p<0.05,{ }^{* *} p<0.01$ two-tailed unpaired Student's $t$-test. (D,E) Representative traces of whole cell current-clamp recordings from granule neurons (D) in acute slices of WT (black) and pre-symptomatic Syn $\mathrm{II}^{-/-}$(red) mice and AP frequency (E) plotted as a function of the injected current for both genotypes. (resting and threshold potential, AP amplitude, half-amplitude width, after-hyperpolarization current) were similar for the two genotypes in both mossy and granule neurons (data not shown). These results indicate that the reduced fPSPs in the hilar region of pre-symptomatic Syn $\mathrm{II}^{-/}$mice (Figure 1) are associated with reduced excitability of Syn $\mathrm{II}^{-/-}$mossy cells, but not granule cells.

\section{ADULT SYN II-/- HILAR MOSSY CELLS RECAPITULATE THE PHENOTYPE OF PRE-SYMPTOMATIC SYN II-/- MICE}

To verify if the reduced excitability of hilar mossy cells in presymptomatic Syn $\mathrm{II}^{-/}$- slices persists after the initiation of epileptic seizures in these mice, we repeated the experiments from Figures 4, 5 on adult (4-6 months old) Syn $\mathrm{II}^{-/-}$mouse slices. As in pre-symptomatic mice, both the amplitude and the frequency distributions of mEPSCs were significantly shifted toward lower values in Syn $\mathrm{II}^{-/-}$hilar mossy neurons $(n=4$ neurons/3 mice for WT and 6 neurons $/ 3$ mice for Syn $\mathrm{II}^{-/-}$; KolmogorovSmirnov test, $p<0.001$ ) (Figures 6A,B). The smaller amplitude distribution of Syn $\mathrm{II}^{-/-}$cells was not accompanied by any change in the kinetic parameters of the response with respect to the WT (rise-time 10-90\%: $1.36 \pm 0.2$ vs. $1.08 \pm 0.1 \mathrm{~ms}, p=$ 0.296 ; decay $\tau: 5.58 \pm 1.1$ vs. $5.63 \pm 0.6 \mathrm{~ms}, p=0.967$; two-tailed unpaired Student's $t$-test) (Figure 6C). Moreover, the firing rate of mossy cells was lower in adult Syn $\mathrm{II}^{-/-}$(Figures 6D,E), with a significant increase in rheobase $(60.0 \pm 5.7, n=3$ neurons $/ 3$ mice for WT vs. $85.0 \pm 8.6 \mathrm{pA}$ for Syn $\mathrm{II}^{-/-}, n=8$ neurons $/ 3$ mice; two-tailed unpaired Student's $t$-test, $p=0.043$ ) (Figure 6F, left) and a decrease in input resistance $(422.0 \pm 12.5 \mathrm{M} \Omega, n=3$ neurons $/ 3$ mice for WT vs. $269.0 \pm 38.0$ for Syn $\mathrm{II}^{-/-}, n=8$ neurons/ 3 mice; two-tailed unpaired Student's $t$-test, $p=0.042$ ) (Figure 6F, right). These results show that the cellular phenotype of Syn $\mathrm{II}^{-/-}$mice appears long before the appearance of an overt epileptic phenotype.

\section{THE INHIBITORY OUTPUT OF HILAR MOSSY CELLS TO GRANULE CELLS IS REDUCED IN BOTH PRE-SYMPTOMATIC AND SYMPTOMATIC SYN II $^{-/-}$MICE}

The axons of hilar mossy cells project into the inner molecular layer of the DG, where they make excitatory synapses directly with granule cells, or with GABA interneurons, leading to disynaptic inhibition of granule cells (Scharfman and Myers, 2012; Jinde 


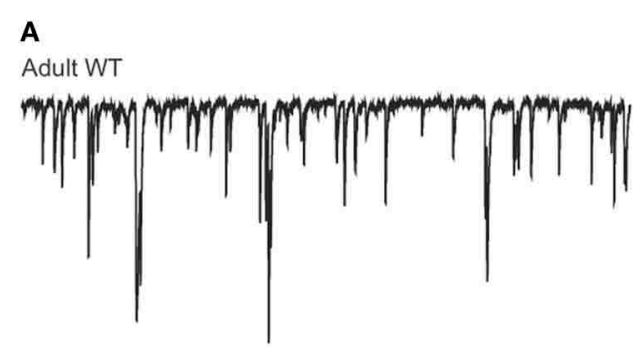

B

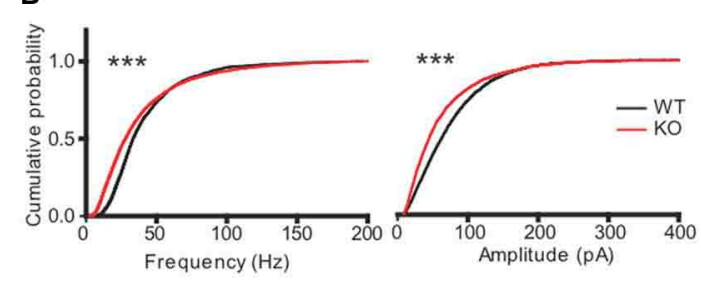

Adult Syn $11-$

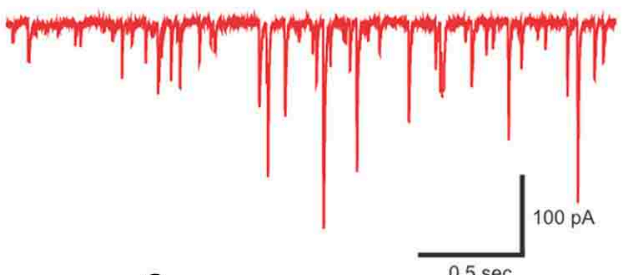

C

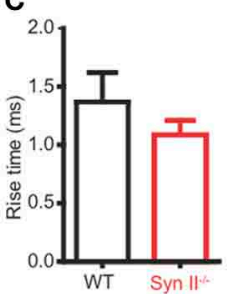

D

Adult WT

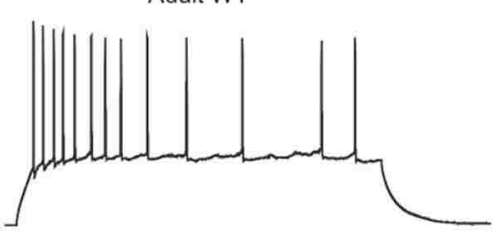

E

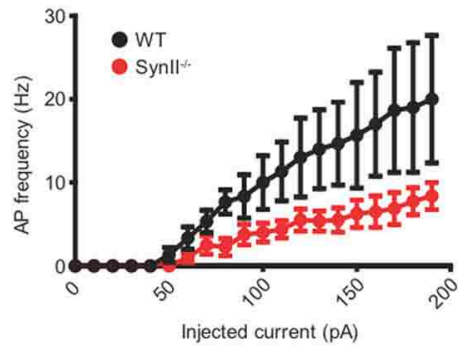

FIGURE 6 | The hilar mossy cell phenotype of pre-symptomatic Syn II-/mice is maintained in adult symptomatic Syn $\mathrm{II}^{-/-}$mice. (A) Representative mEPSC traces (A) and cumulative distributions (B) of their amplitude and frequency from 4 to 6 months old WT (black) and Syn II-/(red) mossy cells; ${ }^{* * *} p<0.001$, Kolmogorov-Smirnov test. (C) Mean ( \pm s.e.m.) rise-time (10-90\%) and mono-exponential $\tau$ of decay of mEPSCs

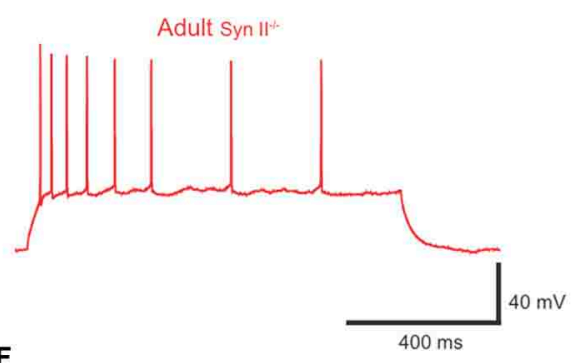

$\mathbf{F}$
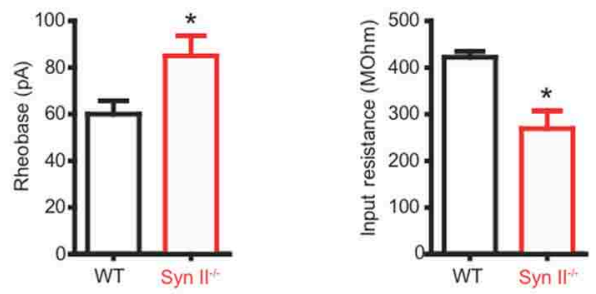

from 4-6 months old WT (black bars) and Syn $\mathrm{II}^{-/-}$(red bars) neurons. (D) Representative traces of current-clamp recordings from hilar mossy neurons in acute slices of WT (black) and symptomatic Syn $\mathrm{II}^{-/-}$(red) mice. (E) Frequency of APs plotted as a function of the injected current for both genotypes. (F) Mean ( \pm s.e.m.) rheobase and input resistance; ${ }^{*} p<0.05$, two-tailed unpaired Student's t-test.

et al., 2013). Since Syn II is abundantly and specifically expressed in the mossy cell terminals of the inner molecular layer (Figure 3), the next step was to evaluate the net effect of the mossy cell output on granule cell activity. To this aim, we patched granule neurons from the granule cell layer and stimulated the axons of mossy cells in the region below the granule layer (Figure 7A). When granule neurons are voltage-clamped at $-80 \mathrm{mV}$, close to the reversal potential of $\mathrm{Cl}^{-}$, the stimulation should result in an evoked excitatory inward response non-contaminated by inhibition. On the contrary, when the clamped voltage is shifted to $0 \mathrm{mV}$, the $\mathrm{Cl}^{-}$ drive will be predominant, and the stimulation should elicit a net inhibitory, outward response representing the fast-forward inhibition resulting from the intermediate activation of GABA interneurons (Figure 7B). Single stimulation did not reveal any difference between the amplitude of both eEPSC and eIPSCs in WT and pre-symptomatic and adult Syn $\mathrm{II}^{-/-}$slices $(n=16 \mathrm{neu}-$ rons/ 6 mice for WT, 10 neurons/4 mice for young Syn $\mathrm{II}^{-/-}$and 13 neurons $/ 3$ mice for adult Syn $\mathrm{II}^{-/-}$; One-Way ANOVA followed by the Bonferroni's multiple comparison test, $p=0.344$ and 0.751 for eEPSCs and eIPSC, respectively) (Figures 7C,D). Instead, the application of a $40 \mathrm{~Hz}$ tetanic stimulation revealed that depression was significantly increased at inhibitory synapses in both young and adult Syn $\mathrm{II}^{-/-}$granule neurons (Figure 7F), while it was similar between genotypes at excitatory synapses (Figure 7E). We quantified this effect by measuring the ratio between the evoked excitatory and inhibitory responses (E/I 
A

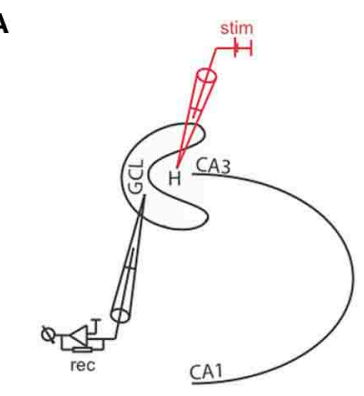

C

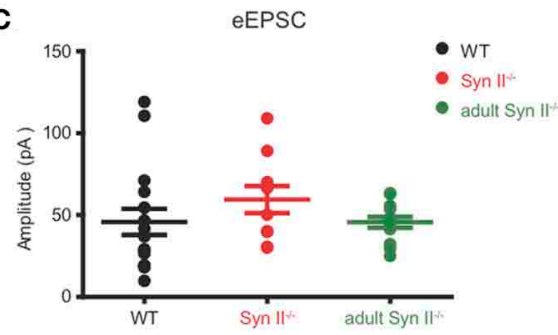

E
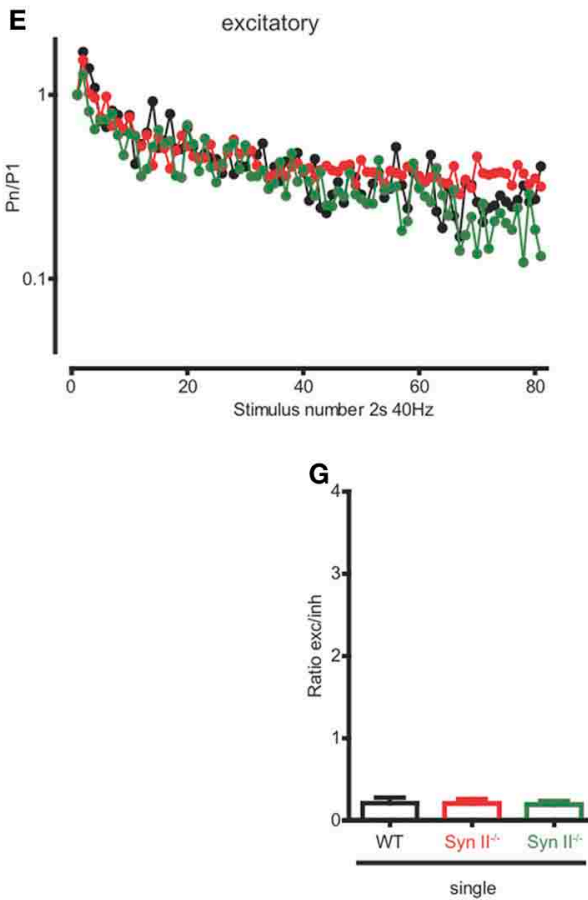

FIGURE 7 | The inhibitory output of hilar mossy cells to granule cells is reduced in both pre-symptomatic and symptomatic Syn $\mathrm{II}^{-/-}$mice. (A) Scheme of the experimental setup. (B) Representative traces of an eEPSC ( $-80 \mathrm{mV}$, inward) and an elPSC $(0 \mathrm{mV}$, outward) recorded in the voltage-clamp configuration from the same pre-symptomatic Syn $\mathrm{II}^{-/-}$granule cell after the stimulation of the perforant path. (C,D) Aligned dot-plots representing the amplitude of the eEPSCs (C) or elPSCs (D) from young WT (black),

pre-symptomatic (red) and symptomatic (green) Syn $\mathrm{I}^{-/-}$mice. (E,F) Plots of

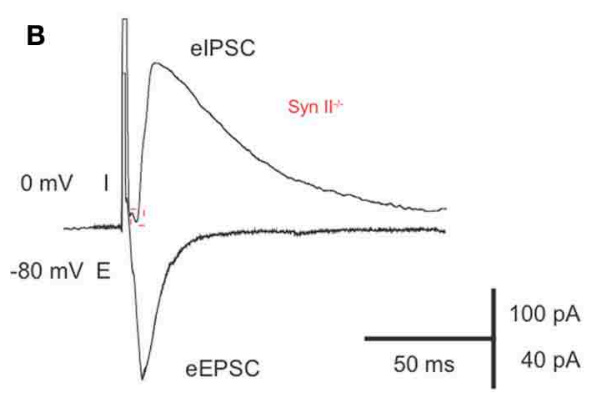

D $\quad$ eIPSC

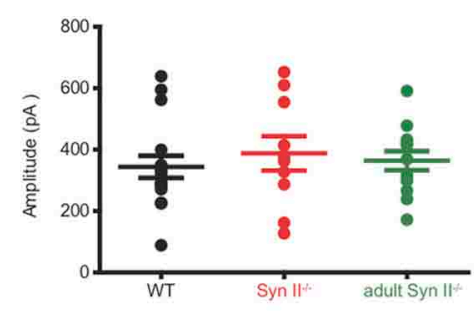

F inhibitory
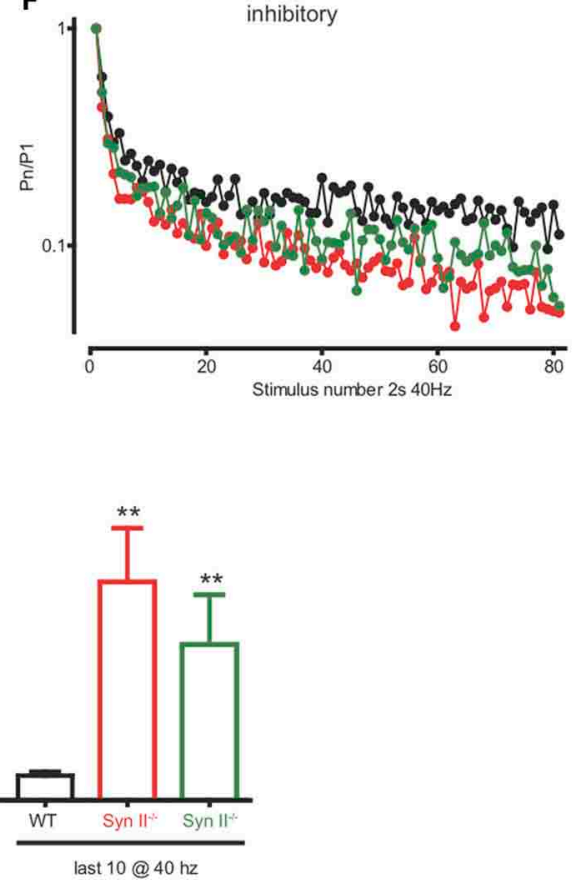

ratio) on the same granule cell. Single pulse stimulation of the mossy cell axon produced postsynaptic inhibitory and excitatory currents whose ratio was similar between genotypes $(p=$ 0.938; One-Way ANOVA followed by the Bonferroni's multiple the normalized mean amplitude of excitatory (E) or inhibitory (F) responses vs. time showing the multiple-pulse depression during a 2-s train at $40 \mathrm{~Hz}$ in young WT (black), pre-symptomatic (red) and symptomatic (green) Syn $\mathrm{I}^{-1-}$ mice. (G) Mean ( \pm s.e.m.) ratio between the amplitudes of eEPSCs and elPSCs from the same granule neurons (young WT, black; pre-symptomatic Syn $\mathrm{I}^{-/-}$, red; symptomatic Syn $\mathrm{I}^{-/-}$, green) in the case of a single stimulus (left) or for the last 10 stimuli in a $40 \mathrm{~Hz}$ train (right); ${ }^{* *} p<0.001$,

Kruskal-Wallis test followed by Dunn's multiple comparison test. 
ratio $=0.3 \pm 0.04$ for $\mathrm{WT}, n=6$ neurons $/ 3$ mice; $2.6 \pm 0.6$ for young Syn $\mathrm{II}^{-/-}, n=7$ neurons $/ 4$ mice; $1.8 \pm 0.6$ for adult Syn $\mathrm{II}^{-/-}, n=6$ neurons $/ 3$ mice; $p=0.0011$; Kruskal-Wallis test followed by the Dunn's multiple comparison test) (Figure 7G, right). This change in the ratio between excitation and inhibition may be responsible for the hyperexcitability of the DG under conditions of sustained high frequency synaptic input, as seen in Figure 2.

\section{DISCUSSION}

Epilepsy affects $1 \%$ of the general population, and $0.5 \%$ of children (Cowan, 2002). In the last 15 years, with the advent of genetic screening of epileptic families, many causative mutations in epileptogenic genes have been identified. The vast majority of these genes code for ion channels, or ion channel auxiliary subunits, with $\mathrm{Na}^{+}$channels as the main "actors" (Gardiner, 1999; Poduri and Lowenstein, 2011). Some mutations have been also found in genes that encode proteins involved in the presynaptic SV release machinery or cell metabolism (Cavalleri et al., 2007; Striano et al., 2008; Suls et al., 2009; Pearl et al., 2011). As a result of these findings, more than 15 transgenic and knockout mouse models have been generated to aid in the study of epilepsy (Mantegazza et al., 2010). These models are superior to pharmacologically induced models. They often closely resemble the human pathology and offer the possibility to study the evolution of the disease and test new therapeutic strategies. These organisms can be studied in the pre-symptomatic phase, to investigate the mechanisms that lead to epileptogenesis, and distinguish them from subsequent secondary mechanisms that lead to the aggravation of symptoms.

As mentioned above, SYN2 alterations in humans seem to confer predisposition for epilepsy. Previous studies have suggested an association of SYN2 rs3773364 A $>$ G polymorphism with febrile seizures in the UK, Irish, and Finnish cohorts (EPIGEN Epilepsy Genetic Consortium; Cavalleri et al., 2007) and in Indian patients with idiopathic epilepsy (Lakhan et al., 2010), but not in the Australian cohort (Cavalleri et al., 2007) or in Malaysian epileptic patients (Haerian et al., 2011). Remarkably, mice lacking one or more Syn isoforms are all prone to epileptic seizures, with the exception of Syn III $^{-/-}$mice (Rosahl et al., 1995; Cesca et al., 2010; Etholm et al., 2011, 2012; Ketzef et al., 2011; Farisello et al., 2013). The model used in the present study is the Syn $\mathrm{II}^{-/-}$mouse developing an overt epileptic phenotype around the age of 2 months (Bogen et al., 2011; Etholm et al., 2011, 2012). It remains unclear why absence of Syn I or II leads to hyperexcitability. An early study (Rosahl et al., 1995) investigated mice lacking Syn I, Syn II, or both isoforms. By using extracellular recordings from CA1 pyramidal neurons, it was shown that paired-pulse facilitation was increased in the Syn $\mathrm{I}^{-/-}$, but not in the Syn $\mathrm{II}^{-/-}$or in the double Syn $\mathrm{I} / \mathrm{II}^{-/-}$ mouse. On the contrary, post-tetanic potentiation was decreased in the latter two genotypes, but not in the Syn $\mathrm{I}^{-/-}$mouse.

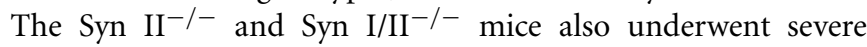
synaptic depression upon repetitive stimulation (Rosahl et al., 1995).

We have recently shown that pre-symptomatic Syn I/II/III ${ }^{-/-}$ mice display an impaired tonic current, due to defects in GABA release and spillover and leading to diffuse hyperexcitability of hippocampal pyramidal neurons (Farisello et al., 2013). A similar study (Ketzef et al., 2011) showed that, increased field responses were elicited in these mice during the pre-symptomatic phase. They further suggest that in pre-symptomatic animals a number of compensatory mechanisms take place that enhance both inhibition and excitation, and eventually culminate with the onset of seizures. In a parallel study (Boido et al., 2010), the action of the antiepileptic drug levetiracetam was investigated in Syn I/II/III ${ }^{-/-}$mouse slices. They used 4 -aminopyridine to evoke epileptic-like events and showed that levetiracetam ameliorated abnormal activity more efficiently in WT than in Syn I/II/III ${ }^{-/-}$ mice. This finding can be explained by the decreased levels of the levetiracetam receptor SV2A due to the marked decrease in SV density observed in these animals (Gitler et al., 2004).

The basic question is why this phenotype appears so late in post-natal development, if other phenotypic traits, such as the sharp loss of the reserve pool of SVs in nerve terminals (Baldelli et al., 2007; Cesca et al., 2010; Lignani et al., 2013), are altered much earlier. This view has been extended by more recent studies showing that Syns are actively involved in postdocking steps of exocytosis, delivering SVs to the active zones and affecting the kinetics and synchronization of release (Hilfiker et al., 1998; Bykhovskaia, 2011; Medrihan et al., 2013). In the case of Syn II, it is interesting that the protein expression profile increases from birth to reach a plateau around postnatal day 60, coinciding with the onset of seizures (Bogen et al., 2011). Thus, it is possible that the overt epileptic phenotype appears only when the synapses require the full expression of Syns to maintain a proper balance between excitatory and inhibitory transmission. Moreover, epileptogenesis is a multifactorial disorder that involves a cascade of molecular, cellular and network alterations occurring over a long time interval after the initial insult (Rakhade and Jensen, 2009; Hunt et al., 2013). The latent phase of epileptogenesis lasts months to years in humans, and between 2 and 12 weeks in rodent models (Rakhade and Jensen, 2009). In the case of a genetic model as Syn $\mathrm{II}^{-/-}$mice, the synaptic dysfunctions during the first 2 months of life hinder the development of a proper balance between excitation and inhibition, eventually leading to seizures. Another important developmental aspect is the expression of GABA receptors and GABA synthetic enzymes that do not reach full expression until before the fourth week of life in rats. Furthermore, it is well known that in the first weeks of life GABA acts as an excitatory neurotransmitter, due to the increased intracellular $\mathrm{Cl}^{-}$ concentration (Rakhade and Jensen, 2009). These aspects could explain the late seizure onset in our mouse model. Although mossy cells have a decreased output and a lower excitatory drive on inhibitory interneurons, this does not significantly alter the interneuron output, since GABA-mediated inhibition is initially weak. This is probably a simplistic explanation, since a number of ion channels, ion pumps and neurotransmitter synthases reach full expression a few weeks after birth in rodents, making it a difficult task to pinpoint one single event that is crucial in seizure onset.

A specific characteristic of temporal lobe epilepsy is the loss of hilar neurons in the hippocampus. It was assumed for a long 
time that mossy cells are the main population to decrease in number, despite the fact that, until very recently, no specific marker to distinguish them from inhibitory interneurons was available. Recent results have shown that hilar mossy cells and GABA-positive interneurons are equally decreased in number in a head trauma epilepsy model (Santhakumar et al., 2000), suggesting that mossy cell survival might be as important as their loss in increasing seizure propensity. Currently, there are several theories regarding the reason why mossy cell loss could lead to hippocampal hyperexcitability. The first one is the "cell loss-induced axonal sprouting" hypothesis (Wenzel et al., 2000). It is based on the fact that granule cell axons massively innervate mossy cells. A partial loss of mossy cells, by triggering mossy fiber sprouting, would abnormally innervate other granule cells and thus create recurrent excitation loops. The second theory is the "dormant basket cell" hypothesis (Sloviter, 1991). This hypothesis proposes a role for mossy cells in exciting the inhibitory basket cells, present in the granule cell layer. A decrease in the number of mossy cells would then lead to a hypoactivation of inhibitory interneurons and to dentate granule cells hyperexcitability. The third theory, the "irritable mossy cell" hypothesis, emphasizes the role of the surviving mossy cells that would undergo various alterations, leading to the amplified activity of the granule cells (Scharfman and Myers, 2012). A more recent theory integrates the latter two (Scharfman and Myers, 2012), basing itself on anatomical data and paired recordings showing that mossy cells synapses preferentially target interneurons locally (Scharfman, 1995) and have projections that extend along the septo-temporal hippocampal axis which mainly synapse on granule cells (Buckmaster et al., 1996). Furthermore, it seems that mossy cells do not connect only with basket cells, but with a range of different inhibitory interneurons also in the hilus. Thus, the role of mossy cells in regulating hippocampal activity is rather complex and difficult to predict.

It is not known which, if any, of these theories represents the true mechanism by which the hippocampus becomes hyperexcitable. An essential aspect is the fact that mossy cells convey feedback from the CA3 pyramidal neurons to the granule cells. This circuit configuration might provide the frame for reverberant activity and the transition from brief, interictal events, to seizure-like activity (Scharfman et al., 2001). To test any of the above-described theories, one would need a tool to specifically eliminate mossy cells from the hippocampus and study the subsequent changes. This experiment was performed by Jinde et al. (2012), who generated a conditional transgenic mouse selectively expressing the diphtheria toxin receptor in the mossy cells. After a few weeks of diphtheria toxin injection in the DG, massive mossy cell degeneration was observed, accompanied by a transient increase in theta power during exploration, deficits in contextual discrimination, and increased anxiety. Patch-clamp recordings of granule cells showed that the frequency, but not the amplitude, of both sEPSCs and sIPSCs was decreased (Jinde et al., 2012). These results strengthen the view that mossy cells convey both direct excitatory and indirect/feed-forward inhibitory input to granule cells, and that the balance between these two inputs plays a key role for the spatial and temporal control of granule cell excitability in the DG. Nonetheless, the animals did not exhibit any epileptiform activity (Jinde et al., 2012), confirming that, as it is in our case, the hypoexcitability of mossy cells is not the sole culprit for epileptic hippocampal activity.

In the present study, we dissected the local expression of Syn II in the mouse hippocampus and showed that it is enriched in regions were granule cell axons project, as well as in the inner molecular layer, where inhibitory synapses from the hilus and granule cell interneurons, and excitatory projections from hilar mossy cells are found. Notably, in this area, the, expression of the mossy cell marker calretinin overlapped with the expression of Syn II (Figure 3). Upon single stimulation of the perforant path in pre-symptomatic Syn $\mathrm{II}^{-/-}$mice we found a decreased field response and a longer latency in the hilus, suggesting impairments in the synaptic release mechanism at mossy fiber terminals and/or a decreased responsiveness of hilar cells. Moreover, synaptic depression in response to tetanic stimulation was significantly decreased in the granule cell layer of the Syn $\mathrm{II}^{-/-}$mice. Based on previous work showing that perforant path activation is similar in Syn $\mathrm{II}^{-/-}$and WT age matched mice (Medrihan et al., 2013) and considering that somatic granule cell properties were unchanged, we suggest that these changes arise from an altered feedback received from the hilar region. Indeed, patch-clamp recordings of mossy cells demonstrated that the dysfunction lies on both sides: on one hand, vesicular release from mossy fibers is reduced, and on the other hand, mossy cell excitability is reduced. These changes appeared before the overt epileptic phenotype and persisted in the adulthood. Finally, the dissection of the excitatory and inhibitory inputs to granule cells from mossy cells revealed that, under conditions of sustained high frequency synaptic activity, the excitation/inhibition ratio is significantly increased in both pre-symptomatic and symptomatic Syn $\mathrm{II}^{-/-}$mice.

It is difficult to explain why the loss of a presynaptic protein leads to decreased excitability of mossy cells. The latter could be the expression of a homeostatic mechanism operating at the level of the hippocampal network that fights against hyperexcitability and absolutely requires the full expression of Syn II when plasticity in the adult brain decreases. This hypothesis suggests that one of the functional roles of Syns I and II, whose expression strongly increases after the first month of postnatal life and remains high throughout adulthood (Lohmann et al., 1978; Bogen et al., 2009), is to provide a high degree of plasticity to the adult synapses.

The functional changes in the DG of the Syn $\mathrm{II}^{-/}$may not be all due to the sole absence of synapsin and high-throughput profiling studies will prove useful to investigate the relative expression of other genes/proteins involved in epileptogenesis. However, these studies would be difficult to design in our case, since the absence of synapsin II may have developmental long term effects on many aspects of the maturation of the hippocampal network. The profiling studies are usually investigating the changes induced by the application of a drug or trauma or a mutation in a transcription/repressor factor that can directly lead to changes in the transcription machinery (Bando et al., 2011; Pernot et al., 2011; Goldberg and Coulter, 2013). In our case any change in DNA/RNA/proteins might reflect adaptive responses to the primary changes in synaptic transmission 
and network excitability induced by the synapsin II mutation. Indeed, the Syn $\mathrm{II}^{-/-}$mouse is characterized, like all other synapsin mutants, by a severe reduction in the density of the SVs, leading to a general decrease in the expression of SV proteins, such as synaptophysin I, SV2 and Rab5 (Rosahl et al., 1995).

Overall, our results reinforce the idea that mossy cells have a predominantly inhibitory effect within the hippocampus, through feedback inhibition on granule cells and that impairments in their function could trigger, or participate in an excitation/inhibition imbalance at the level of the DG of the hippocampus that represents a key factor for epilepsy predisposition. However, epileptogenesis is a multifactorial process that follows a precise temporal sequence of events in most animal models of epilepsy (pilocarpine, kindling, trauma) leading to progressive neural circuitry alterations (Rakhade and Jensen, 2009; Hunt et al., 2013). Thus, our findings suggest that the hypoexcitability of mossy cells is just one factor among others that weakens the DG circuitry and renders it more prone to hyperexcitability in the animal adult. Studies on

\section{REFERENCES}

Amaral, D. G., Scharfman, H. E., and Lavenex, P. (2007). The dentate gyrus: fundamental neuroanatomical organization (dentate gyrus for dummies). Prog. Brain Res. 163, 3-22. doi: 10.1016/S0079-6123(07) 63001-5

Baldelli, P., Fassio, A., Valtorta, F., and Benfenati, F. (2007). Lack of synapsin I reduces the readily releasable pool of synaptic vesicles at central inhibitory synapses. J. Neurosci. 27, 13520-13531. doi: $\quad 10.1523 /$ JNEUROSCI.31 51-07.2007

Bando, S. Y., Alegro, M. C., Amaro, E. Jr., Silva, A. V., Castro, L. H., Wen, H. T., et al. (2011). Hippocampal CA3 transcriptome signature correlates with initial precipitating injury in refractory mesial temporal lobe epilepsy. PLoS ONE 6:e26268. doi: 10.1371/journal.pone.0026268

Benfenati, F., Valtorta, F., Chieregatti, E., and Greengard, P. (1992). Interaction of free and synaptic vesicle-bound synapsin I with F-actin. Neuron 8, 377-386. doi: 10.1016/0896-6273(92)90303-U

Blasco-Ibanez, J. M., and Freund, T. F. (1997). Distribution, ultrastructure, and connectivity of calretinin-immunoreactive mossy cells of the mouse dentate gyrus. Hippocampus 7, 307-320. doi: 10.1002/(SICI) 1098-1063

Bogen, I. L., Jensen, V., Hvalby, O., and Walaas, S. I. (2009). Synapsin-dependent development of glutamatergic synaptic vesicles and presynaptic plasticity in postnatal mouse brain. Neuroscience 158, 231-241. doi: $\quad 10.1016 /$ j.neuroscience.2008. 05.055

Bogen, I. L., Jensen, V., Hvalby, O., and Walaas, S. I. (2011). Glutamatergic neurotransmission in the synapsin I and II double knock-out mouse. Semin. Cell Dev. Biol. 22, 400-407. doi: 10.1016/j.semcdb.2011.07.004

Boido, D., Farisello, P., Cesca, F., Ferrea, E., Valtorta, F., Benfenati, F., et al. (2010). Cortico-hippocampal hyperexcitability in synapsin I/II/III knockout mice: agedependency and response to the antiepileptic drug levetiracetam. Neuroscience 171, 268-283. doi: $\quad 10.1016 /$ j.neuroscience.2010. 08.046

Buckmaster, P. S., Wenzel, H. J., Kunkel, D. D., and Schwartzkroin, P. A. (1996). Axon arbors and synaptic connections of hippocampal mossy cells in the rat in vivo. J. Comp. Neurol. 366, 271-292.

Buzsaki, G., Anastassiou, C. A., and Koch, C. (2012). The origin of extracellular fields and currentsEEG, ECoG, LFP and spikes. Nat. Rev. Neurosci. 13, 407-420. doi: 10.1038/nrn3241

Bykhovskaia, M. (2011). Synapsin regulation of vesicle organization and functional pools. Semin. Cell Dev. Biol. 22, 387-392. doi: 10.1016/j.semcdb.2011.07.003

Cavalleri, G. L., Weale, M. E., Shianna, K. V., Singh, R., Lynch, J. M., Grinton, B., et al. (2007). Multicentre search for genetic susceptibility loci in sporadic epilepsy syndrome and seizure types: a case-control study. Lancet. Neurol. 6, 970-980. doi: 10.1016/S1474-4422(07)70247-8

experimental models of epilepsy, such as the Syn $\mathrm{II}^{-/-}$mouse, could shed light on the complex synaptic mechanisms orchestrating network excitability and contribute to ameliorate diagnosis and prognosis of idiopathic epilepsy linked to synaptic abnormalities.

\section{ACKNOWLEDGMENTS}

We thank Drs. Hung-Teh Kao (Brown University, Providence, RI) and Paul Greengard (The Rockefeller University, New York, NY) for providing us with the Syn II mutant mouse strain. We also thank Dr. Gabriele Lignani and Federico Pecoraro for help with the experiments and useful discussions. This study was supported by research grants from the Italian Ministry of University and Research (PRIN to Fabio Benfenati and Pietro Baldelli), the Italian Ministry of Health Progetto Giovani (to Pietro Baldelli) and the Compagnia di San Paolo, Torino (to Fabio Benfenati and Pietro Baldelli). The support of Telethon-Italy (Grant GGP09134 to Fabio Benfenati and GGP09066 to Pietro Baldelli) is also acknowledged.

Cesca, F., Baldelli, P., Valtorta, F., and Benfenati, F. (2010). The synapsins: key actors of synapse function and plasticity. Prog. Neurobiol. 91, 313-348. doi: 10.1016/j.pneurobio.2010.04.006

Coleman, W. L., Bill, C. A., SimsekDuran, F., Lonart, G., Samigullin, D., and Bykhovskaia, M. (2008). Synapsin II and calcium regulate vesicle docking and the crosstalk between vesicle pools at the mouse motor terminals. J. Physiol. 586, 4649-4673. doi: 10.1113/jphysiol.2008.154666

Cowan, L. D. (2002). The epidemiology of the epilepsies in children. Ment. Retard. Dev. Disabil. Res. Rev. 8, 171-181. doi: 10.1002/mrdd.10035

Etholm, L., Bahonjic, E., Walaas, S. I., Kao, H. T., and Heggelund, P. (2012). Neuroethologically delineated differences in the seizure behavior of Synapsin 1 and Synapsin 2 knock-out mice. Epilepsy Res. 99, 252-259. doi: 10.1016/j.eplepsyres. 2011.12.004

Etholm, L., Linden, H., Eken, T., and Heggelund, P. (2011). Electroencephalographic characterization of seizure activity in the synapsin I/II double knockout mouse. Brain Res. 1383, 270-288. doi: 10.1016/j.brainres. 2011.01.070

Farisello, P., Boido, D., Nieus, T., Medrihan, L., Cesca, F., Valtorta, F., et al. (2013). Synaptic and extrasynaptic Origin of the excitation/inhibition imbalance in the hippocampus of synapsin I/II/III knockout mice. Cereb. Cortex 23, 581-593. doi: 10.1093/cercor/ bhs041
Fassio, A., Raimondi, A., Lignani, G., Benfenati, F., and Baldelli, P. (2011). Synapsins: from synapse to network hyperexcitability and epilepsy. Semin. Cell Dev. Biol. 22, 408-415. doi: $\quad 10.1016 /$ j.semcdb.2011. 07.005

Ferrea, E., Maccione, A., Medrihan, L., Nieus, T., Ghezzi, D., Baldelli, P., et al. (2012). Large-scale, high-resolution electrophysiological imaging of field potentials in brain slices with microelectronic multielectrode arrays. Front. Neural. Circuits 6:80. doi: 10.3389/fncir.2012.00080

Gardiner, R. M. (1999). Genetic basis of the human epilepsies. Epilepsy Res. 36, 91-95. doi: 10.1016/S09201211(99)00043-1

Garriga-Canut, M., Schoenike, B., Qazi, R., Bergendahl, K., Daley, T. J., Pfender, R. M., et al. (2006). 2Deoxy-D-glucose reduces epilepsy progression by NRSF-CtBPdependent metabolic regulation of chromatin structure. Nat. Neurosci. 9, 1382-1387. doi: 10.1038/ nn1791

Giovedi, S., Darchen, F., Valtorta, F., Greengard, P., and Benfenati, F. (2004). Synapsin is a novel Rab3 effector protein on small synaptic vesicles. II. Functional effects of the Rab3A-synapsin I interaction. J. Biol. Chem. 279, 43769-43779. doi: 10.1074/jbc.M404168200

Gitler, D., Cheng, Q., Greengard, P., and Augustine, G. J. (2008). Synapsin IIa controls the reserve pool of glutamatergic synaptic vesicles. J. Neurosci. 28, 10835-10843. doi: $\quad 10.1523 / J N E U R O S C I .09$ 24-08.2008 
Gitler, D., Takagishi, Y., Feng, J., Ren, Y., Rodriguiz, R. M., Wetsel, W. C., et al. (2004). Different presynaptic roles of synapsins at excitatory and inhibitory synapses. J. Neurosci. 24, 11368-11380. doi: 10.1523/JNEUROSCI.3795-04.2004

Goldberg, E. M., and Coulter, D. A. (2013). Mechanisms of epileptogenesis: a convergence on neural circuit dysfunction. Nat. Rev. Neurosci. 14, 337-349. doi: 10.1038/nrn3482

Greco, B., Manago, F., Tucci, V., Kao, H. T., Valtorta, F., and Benfenati, F. (2013). Autism-related behavioral abnormalities in synapsin knockout mice. Behav. Brain Res. 251, 65-74. doi: 10.1016/j.bbr.2012.12.015

Gutnick, M. J., Connors, B. W., and Prince, D. A. (1982). Mechanisms of neocortical epileptogenesis in vitro. J. Neurophysiol. 48, 1321-1335.

Haerian, B. S., Lim, K. S., Tan, H. J., Wong, C. P., Wong, S. W., Tan, C. T., et al. (2011). Lack of association between synapsin II (SYN2) gene polymorphism and susceptibility epilepsy: a case-control study and meta-analysis. Synapse 65, 1073-1079. doi: 10.1002/syn. 20939

Henze, D. A., and Buzsaki, G. (2007). Hilar mossy cells: functional identification and activity in vivo. Prog. Brain Res. 163, 199-216. doi: $10.1016 / 50079-6123$ (07)63012-X

Hilfiker, S., Schweizer, F. E., Kao, H. T., Czernik, A. J., Greengard, P., and Augustine, G. J. (1998). Two sites of action for synapsin domain $E$ in regulating neurotransmitter release. Nat. Neurosci. 1, 29-35. doi: $10.1038 / 229$

Hsu, D. (2007). The dentate gyrus as a filter or gate: a look back and a look ahead. Prog. Brain Res. 163, 601-613. doi: 10.1016/S00796123(07)63032-5

Hunt, R. F., Boychuk, J. A., and Smith, B. N. (2013). Neural circuit mechanisms of post-traumatic epilepsy. Front. Cell Neurosci. 7:89. doi: 10.3389/fncel.2013.00089

Jinde, S., Zsiros, V., Jiang, Z., Nakao, K., Pickel, J., Kohno, K., et al. (2012). Hilar mossy cell degeneration causes transient dentate granule cell hyperexcitability and impaired pattern separation. Neuron 76, 1189-1200. doi: 10.1016/j.neuron.2012.10.036

Jinde, S., Zsiros, V., and Nakazawa, K. (2013). Hilar mossy cell circuitry controlling dentate granule cell excitability. Front. Neural. Circuits 7:14. doi: 10.3389/fncir.2013. 00014
Kao, H. T., Porton, B., Hilfiker, S., Stefani, G., Pieribone, V. A., Desalle, R., et al. (1999). Molecular evolution of the synapsin gene family. J. Exp. Zool. 285, 360-377.

Ketzef, M., Kahn, J., Weissberg, I., Becker, A. J., Friedman, A., and Gitler, D. (2011). Compensatory network alterations upon onset of epilepsy in synapsin triple knock-out mice. Neuroscience 189, 108-122. doi: $10.1016 /$ j.neuroscience. 2011 . 05.030

Lakhan, R., Kalita, J., Misra, U. K., Kumari, R., and Mittal, B. (2010). Association of intronic polymorphism rs3773364 $A>G$ in synapsin-2 gene with idiopathic epilepsy. Synapse 64, 403-408. doi: 10.1002/syn. 20740

Lignani, G., Raimondi, A., Ferrea, E., Rocchi, A., Paonessa, F., Cesca, F., et al. (2013). Epileptogenic Q555x Syn1 mutant triggers imbalances in release dynamics and shortterm plasticity. Hum. Mol. Genet. 22, 2186-2199. doi: $10.1093 / \mathrm{hmg} /$ ddt071

Liu, Y. B., Ye, G. L., Liu, X. S., Pasternak, J. F., and Trommer, B. L. (1998). GABAA currents in immature dentate gyrus granule cells. J. Neurophysiol. 80, 2255-2267.

Lohmann, S. M., Ueda, T., and Greengard, P. (1978). Ontogeny of synaptic phosphoproteins in brain. Proc. Natl. Acad. Sci. U.S.A. 75, 4037-4041. doi: 10.1073/pnas.75.8.4037

Mantegazza, M., Rusconi, R., Scalmani, P., Avanzini, G., and Franceschetti, S. (2010). Epileptogenic ion channel mutations: from bedside to bench and, hopefully, back again. Epilepsy Res. 92, 1-29. doi: 10.1016/j.eplepsyres.2010.08.003

Medrihan, L., Cesca, F., Raimondi, A., Lignani, G., Baldelli, P., and Benfenati, F. (2013). Synapsin II desynchronizes neurotransmitter release at inhibitory synapses by interacting with presynaptic calcium channels. Nat. Commun. 4, 1512. doi: 10.1038/ ncomms 2515

Menegon, A., Bonanomi, D., Albertinazzi, C., Lotti, F., Ferrari, G., Kao, H. T., et al. (2006). Protein kinase a-mediated synapsin I phosphorylation is a central modulator of Ca2+-dependent synaptic activity. J. Neurosci. 26, 11670-11681. doi: $\quad 10.1523 /$ JNEUROSCI.332 1-06.2006

Messa, M., Congia, S., Defranchi, E., Valtorta, F., Fassio, A., Onofri, F., et al. (2010). Tyrosine phosphorylation of synapsin I by Src regulates synaptic-vesicle trafficking. J. Cell Sci. 123, 2256-2265. doi: $10.1242 /$ jcs. 068445

Nadler, J. V. (1987). Sodium-dependent proline uptake in the rat hippocampal formation: association with ipsilateral-commissural projections of CA3 pyramidal cells. J. Neurochem. 49, 1155-1160. doi: 10.1111/j.14714159.1987.tb10006.x

Okamoto, O. K., Janjoppi, L., Bonone, F. M., Pansani, A. P., Da Silva A. V., Scorza, F. A., et al. (2010) Whole transcriptome analysis of the hippocampus: toward a molecular portrait of epileptogenesis. BMC Genomics 11:230. doi 10.1186/1471-2164-11-230

Pearl, P. L., Shukla, L., Theodore, W. H., Jakobs, C., and Michael Gibson, K. (2011). Epilepsy in succinic semialdehyde dehydrogenase deficiency, a disorder of GABA metabolism. Brain Dev. 33, 796-805. doi 10.1016/j.braindev.2011.04.013

Pernot, F., Heinrich, C., Barbier, L., Peinnequin, A., Carpentier P., Dhote, F., et al. (2011). Inflammatory changes during epileptogenesis and spontaneous seizures in a mouse model of mesiotemporal lobe epilepsy. Epilepsia 52, 2315-2325. doi: 10.1111/j.1528-1167.2011.03273.x

Poduri, A., and Lowenstein, D. (2011). Epilepsy genetics-past, present, and future. Curr. Opin. Genet. Dev. 21, 325-332. doi: 10.1016/j.gde.2011.01.005

Rakhade, S. N., and Jensen, F. E. (2009). Epileptogenesis in the immature brain: emerging mechanisms. Nat. Rev. Neurol. 5, 380-391. doi: 10.1038/nrneurol.2009.80

Ratzliff, A., Santhakumar, V., Howard, A., and Soltesz, I. (2002). Mossy cells in epilepsy: rigor mortis or vigor mortis? Trends Neurosci. 25, 140-144. doi: 10.1016/S0166-2236(00)02122-6

Rosahl, T. W., Spillane, D., Missler, M., Herz, J., Selig, D. K., Wolff, J. R., et al. (1995). Essential functions of synapsins I and II in synaptic vesicle regulation. Nature $375,488-493$. doi: $10.1038 / 375488 \mathrm{a} 0$

Santhakumar, V., Bender, R., Frotscher, M., Ross, S. T., Hollrigel, G. S., Toth, Z., et al. (2000). Granule cell hyperexcitability in the early post-traumatic rat dentate gyrus: the 'irritable mossy cell' hypothesis. J. Physiol. 524(Pt 1), 117-134. doi: $\quad 10.1111 /$ j.1469-7793.2000 00117.x

Scharfman, H. E. (1995). Electrophysiological evidence that dentate hilar mossy cells are excitatory and innervate both granule cells and interneurons. $J$. Neurophysiol. 74, 179-194.

Scharfman, H. E., and Myers, C. E. (2012). Hilar mossy cells of the dentate gyrus: a historical perspective. Front. Neural. Circuits 6:106. doi: 10.3389/fncir.2012.00106

Scharfman, H. E., Smith, K. L., Goodman, J. H., and Sollas, A. L. (2001). Survival of dentate hilar mossy cells after pilocarpineinduced seizures and their synchronized burst discharges with area CA3 pyramidal cells. Neuroscience 104, 741-759. doi: 10.1016/S0306-4522(01)00132-4

Schwartzkroin, P. A. (1994). Cellular electrophysiology of human epilepsy. Epilepsy Res. 17, 185-192. doi: $\quad 10.1016 / 0920-1211(94)$ 90049-3

Sloviter, R. S. (1991). Permanently altered hippocampal structure, excitability, and inhibition after experimental status epilepticus in the rat: the "dormant basket cell" hypothesis and its possible relevance to temporal lobe epilepsy. Hippocampus 1, 41-66. doi: 10.1002/hipo.450010106

Striano, P., De Falco, A., Diani, E., Bovo, G., Furlan, S., Vitiello, L., et al. (2008). A novel loss-of-function LGI1 mutation linked to autosomal dominant lateral temporal epilepsy. Arch. Neurol. 65, 939-942. doi: 10.1001/archneur.65.7.939

Suls, A., Mullen, S. A., Weber, Y. G., Verhaert, K., Ceulemans, B., Guerrini, R., et al. (2009). Earlyonset absence epilepsy caused by mutations in the glucose transporter GLUT1. Ann. Neurol. 66, 415-419. doi: 10.1002/ana.21724

Turski, W. A., Cavalheiro, E. A., Schwarz, M., Czuczwar, S. J., Kleinrok, Z., and Turski, L. (1983). Limbic seizures produced by pilocarpine in rats: behavioural, electroencephalographic and neuropathological study. Behav. Brain Res. 9, 315-335. doi: 10.1016/0166-4328(83)90136-5

Valente, P., Casagrande, S., Nieus, T., Verstegen, A. M., Valtorta, F., Benfenati, F., et al. (2012). Site-specific synapsin I phosphorylation participates in the expression of post-tetanic potentiation and its enhancement by BDNF. J. Neurosci. 32, 5868-5879. doi: $\quad 10.1523 /$ JNEUROSCI.52 75-11.2012

Voskuyl, R. A., and Albus, H. (1985). Spontaneous epileptiform discharges in hippocampal slices induced by 4 -aminopyridine. 
Brain Res. 342, 54-66. doi: 10.1016/0006-8993(85)91352-6

Wenzel, H. J., Woolley, C. S., Robbins, C. A., and Schwartzkroin, P. A. (2000). Kainic acid-induced mossy fiber sprouting and synapse formation in the dentate gyrus of rats. Hippocampus 10, 244-260.

Westerhoff, C. H., Domann, R., and Witte, O. W. (1995). Inhibitory mechanisms in epileptiform activity induced by low magnesium. Pflugers Arch. 430, 238-245. doi: 10.1007/BF00374655

Wilson, D. H., Reeves, A., Gazzaniga, M., and Culver, C. (1977). Cerebral commissurotomy for control of intractable seizures. Neurology 27, 708-715. doi: 10.1212/WNL.27. 8.708

Witte, O. W. (1994). Afterpotentials of penicillin-induced epileptiform neuronal discharges in the motor cortex of the rat in vivo. Epilepsy Res. 18, 43-55. doi: 10.1016/0920-1211(94) 90032-9

Conflict of Interest Statement: The authors declare that the research was conducted in the absence of any commercial or financial relationships that could be construed as a potential conflict of interest.

Received: 30 April 2013; accepted: 08 August 2013; published online: 30 August 2013.

Citation: Toader O, Forte N, Orlando $M$, Ferrea E, Raimondi A, Baldelli P, Benfenati $F$ and Medrihan L (2013) Dentate gyrus network dysfunctions precede the symptomatic phase in a genetic mouse model of seizures. Front. Cell. Neurosci. 7:138. doi: 10.3389/fncel. 2013.00138

This article was submitted to the journal Frontiers in Cellular Neuroscience.
Copyright (C) 2013 Toader, Forte, Orlando, Ferrea, Raimondi, Baldelli, Benfenati and Medrihan. This is an open-access article distributed under the terms of the Creative Commons Attribution License (CCBY). The use, distribution or reproduction in other forums is permitted, provided the original author(s) or licensor are credited and that the original publication in this journal is cited, in accordance with accepted academic practice. No use, distribution or reproduction is permitted which does not comply with these terms. 